Research article

urn:1sid:zoobank.org:pub:00B57E96-225C-4646-9CB8-B3514C4EC7E5

\title{
A revision of the Chinese Helochares (s. str.) Mulsant, 1844 (Coleoptera, Hydrophilidae)
}

\author{
Fenglong JIA ${ }^{1, *} \&$ Yu-dan TANG $^{2}$ \\ ${ }^{1,2}$ Institute of Entomology, Life Science School, Sun Yat-sen University, \\ Guangzhou, 510275, Guangdong, China. \\ *Corresponding author: 1ssjfl@mail.sysu.edu.cn; fenglongjia@aliyun.com \\ ${ }^{2}$ Email: 804586571@qq.com \\ ${ }^{1}$ urn:lsid:zoobank.org:author:AD2EFC37-9653-4965-894A-97317A616A48 \\ ${ }^{2}$ urn:1sid:zoobank.org:author:E7D3E5C2-26A7-4B25-B3E1-5774BD239F8D
}

\begin{abstract}
Representatives of the subgenus Helochares (s. str.) Mulsant, 1844 of China are revised. One new species, $H$. (s. str.) songi sp. nov., is described from Guangxi, China. All species known from China are redescribed. A diagnosis and a differential diagnosis are provided for each species. Helochares fuliginosus d'Orchymont, 1932 is recorded for the first time from China and Cambodia. Additional distribution records of H. atropiceus Régimbart, 1903 and H. pallens (MacLeay, 1825) are provided from China. The habitus and aedeagus of all species are illustrated, and a key for the identification of Chinese species of the subgenus is provided.
\end{abstract}

Keywords. Hydrophilidae, new species, China, Oriental, Palaearctic.

Jia F. \& Tang Y. 2018. A revision of the Chinese Helochares (s. str.) Mulsant, 1844 (Coleoptera, Hydrophilidae). European Journal of Taxonomy 438: 1-27. https://doi.org/10.5852/ejt.2018.438

\section{Introduction}

The genus Helochares Mulsant, 1844 currently contains 180 described species that are assigned to five subgenera (Hansen 1999; Short \& Hebauer 2006; Short \& Fikáček 2011). The genus is distributed worldwide, with the highest species diversity recorded from the Afrotropical, Oriental, Neotropical and Australian regions. Of the five subgenera, Sindolus Sharp, 1882 is known only from the Neotropical region, Helocharimorphus Kuwert, 1890 and Batochares Hansen, 1991 only from the Afrotropical region, and Hydrobaticus MacLeay, 1871 and Helochares (s. str.) are known from all zoological realms. Since the publication of the World Catalogue of Hydrophiloidea (Hansen 1999), 27 new species have been described and 4 species were treated as synonyms. In the subgenus Helochares (s. str.), 10 species have been described from the Oriental, Afrotropical and Neotropical regions since 1999 (Hebauer 1999, 2001, 2002, 2003; Hebauer et al. 1999; Short 2005; Mart et al. 2010). A total of 40 species of Helochares (s. str.) have now been described, 14 of which occur in the Neotropics, 11 in the Afrotropical region, 8 in the Palearctic, 7 in the Oriental region, 3 in Australia and only 1 species in the Nearctic (Hansen 1999; Short \& Hebauer 2006; Short \& Fikáček 2011). 
The Chinese fauna of Helochares (s. str.) is poorly known. Only three species have been recorded from China: H. (s. str.) pallens (MacLeay, 1825) (d'Orchymont 1935), H. (s. str.) obscurus (Müller, 1776) (Fikáček et al. 2015) and H. (s. str.) atropiceus Régimbart, 1903 (Jia et al. 2010; Fikáček et al. 2015).

\section{Material and methods}

Some specimens of each species were dissected. After $8-10$ hours in $10 \% \mathrm{KOH}$ at room temperature, male genitalia were transferred to a drop of distilled water, the remaining membrane was removed under a compound microscope, and the cleaned genitalia were subsequently mounted in a drop of glycerin on a piece of transparent plastic attached below the specimens. Male genitalia and morphological characters were examined using a Nikon SMZ800 compound microscope. Photographs were taken using a Zeiss Axioskop 40 compound microscope combined with AutoMontage software and a Leica M205C stereo microscope. Morphological terminology largely follows Hansen (1991) and Komarek (2004).

Examined specimens are deposited in the following collections:

BMNH $=$ The Natural History Museum, London, UK

IRSN = Institut royal des Sciences naturelles, Brussels, Belgium

$\mathrm{KMNH}=$ Kitakyushu Museum of Natural History and Human History, Kitakyushu, Japan

NMPC = National Museum, Prague, Czech Republic

SYSU = Entomological collection of Sun Yat-sen University, Guangzhou, China

Specimens for which the depository is not indicated are all deposited in SYSU.

We also checked a paratype of Helochares (s. str.) vitalisi d'Orchymont, 1919 (d'Orchymont 1919a), a species known only from Cambodia, in order to compare it with the Chinese species $H$. songi sp. nov. The original label for the paratype states: "Paratype: unsexed (IRSN): Long Xuyen/Cochinchine/Dorr. // H. Vitalisi/d'orchym. // Coll. d'Orchy."

\section{Results}

Class Hexapoda Blainville, 1816

Order Coleoptera Linnaeus, 1758

Family Hydrophilidae, Latreille, 1802

Subfamily Acidocerinae Zaitzev, 1908

Genus Helochares Mulsant, 1844

Subgenus Helochares (s. str.) Mulsant, 1844

Enhydrus Dahl, 1823: 34 (nom. nud.).

Enhydrus MacLeay, 1825: 35.

Helophilus Mulsant, 1844: 132.

Helochares Mulsant, 1844: 197.

Pylophilus Motschulsky, 1845: 32 (type species: Hydrophilus griseus Fabricius, 1787).

Peloxenus Motschulsky, 1845: 549 (type species: Hydrophilus griseus Fabricius, 1787).

Helophygas Motschulsky, 1853: 11.

Stagnicola Montrouzier, 1860: 246 (type species: Stagnicola foveicollis Montrouzier, 1860). — Bedel 1881: 311 (synonymization).

Neohydrobius Blackburn, 1898: 221 (type species: Philhydrus burrundiensis Blackburn, 1890 by monotypy). — d'Orchymont 1919c: 228 (synonymization). 


\section{Diagnosis}

The following character combination can be used to separate Helochares (s. str.) from other subgenera of Helochares: (1) maxillary palps at least as long as width of head (shorter than width of head in subgenus Helocharimorphus); (2) second maxillary palpomeres clearly curved inwards, apical segment at most as long as penultimate segment; (3) mesoventrite bulging medially, without strongly raised process (subgenus Sindolus with strongly raised process); (4) elytra without striae or serial punctures and without scutellary stria, but with rows of systematic punctures (subgenera Hydrobaticus and Batochares with 8-10 striae or series of punctures and short scutellary stria); (5) elytra without sutural striae; and (6) posterior margin of last visible abdominal sternite with apical emargination fringed with stiff yellowish setae (subgenus Batochares without apical emargination).

For keys to the subgenera of Helochares Mulsant, see Hebauer (1996) and d'Orchymont (1919b).

Helochares songi sp. nov. urn:1sid:zoobank.org:act:2B1792C1-5D59-46B2-AE98-3440BA2FED57

Figs 1-8, 48-49

\section{Diagnosis}

Length 4.8-5.3 mm, width 2.6-2.9 mm. Dark brown or black (Fig. 1), clypeus uniformly dark brown to black (Fig. 4), anterior half of lateral margin of pronotum yellowish brown (Figs 1, 3-4, 6), elytra uniformly dark brown to black (Fig. 3). Dorsum with uniform dense and coarse ground punctures. Clypeus moderately expanded laterally, with somewhat rounded lateral margin, clearly impressed in front of eyes (Fig. 4). Maxillary palps ca $1.2 \times$ as long as width of head, dark brown to black, each palpomere with light colour apically (Figs 1-2,4). Pedicel subequal in length to antennomeres 3-6 combined. Submentum with a small glabrous area medially and with a few coarse punctures laterally (Fig. 5). Elytra almost parallel from base to posterior third, somewhat explanate laterally, with distinct systematic punctures (Fig. 3). Mesoventrite with a low transverse ridge medially and a low longitudinal carina (Fig. 7). Metaventrite without glabrous area medially. Femora densely pubescent except for apical eighth (Figs 2,8). Aedeagus slender, length of paramere ca $10 \times$ as long as width of apex (Fig. 48), subparallel, apex with a small tooth inwards (Figs 48-49); apex of median lobe slightly overlapping parameres; basal strut of median lobe long, ca $1 / 3 \times$ as long as parameres (Fig. 48).

\section{Etymology}

The specific name is given in honor of Keqing Song, the collector of the type specimens.

\section{Material examined}

\section{Holotype}

CHINA: 1 ô, Guangxi Province, Shiwandashan, Nalin River, $316 \mathrm{~m}$ a.s.1., in water at edge of upper river, 21 Jul. 2011, Keqing Song leg. (SYSU).

\section{Paratypes (77 spec., BMNH, KMNH, NMPC, SYSU)}

CHINA: Guangxi: $2 \hat{\jmath}, 4 \uparrow+, 15$ spec., same collection data as for holotype; 3 spec., Shiwandashan, Forest Park, 239 m a.s.l., edge of upper river, 19 Jul. 2011, Keqing Song leg.; 11 spec., Shiwandashan, Forest Park, edge of river, 17 Aug. 2011, Keqing Song leg.; 3 spec., Shiwandashan, Forest Park, $221 \mathrm{~m}$ a.s.1., in water at edge of lower stone river, 12 Jul. 2011, Keqing Song leg.; 20 spec., Shiwandashan, 430 m a.s.l., edge of Nalinhe River (in water), 21 Jul. 2011, Keqing Song leg.; 19 spec., Shiwandashan, 269 m a.s.l., edge of river outside Forest Park, 20 Jul. 2011, Keqing Song leg. (BMNH, KMNH, NMPC, SYSU). 


\section{Description}

Form AND COLOUR. Body oval, length 4.8-5.3 mm, width 2.6-2.9 mm, moderately convex. Head dark brown to black. Pronotum dark brown to black, anterior half with narrow yellowish brown lateral margins (Figs 1, 3-4, 6). Elytra uniformly dark brown to black (Figs 1, 3). Maxillary palps dark brown to black, each palpomere light yellowish brown apically (Figs 1-2,4). Labial palpomeres yellow to yellowish brown. Antennae yellowish brown, club with dense yellow setae. Ventral side dark brown or black (Fig. 2), legs with same colour as ventral side, but with reddish to yellowish brown tarsomeres (Fig. 2).

HEAD. Labrum with fine and dense punctures, smooth between punctures, anterior margin broadly emarginate. Clypeus broad, anterior margin clearly broadly emarginate, moderately expanded in front of eyes, with somewhat rounded lateral margin (Fig. 4), clearly impressed in front of eyes (Fig. 4). Ground punctures on clypeus coarser and sparser than those on labrum, surface smooth between punctures. Systematic punctures on clypeus almost same size as ground punctures. Eyes of moderate size, clearly emarginate anteriorly (Figs 1,4 ), separated by ca $4.0-4.1 \times$ the width of one eye. Frons with slightly coarser and stronger punctures than on clypeus, with clear systematic punctures. Maxillary palps long and slender, ca 1.1-1.2 $\times$ as wide as head, second and third palpomeres curved inwards, apical palpomere almost as long as penultimate, asymmetrical (Fig. 4). Antennae with 9 antennomeres, scape ca $1.5 \times$ as long as pedicel, pedicel subequal in length to antennomeres 3-6 combined, club loosely segmented, with dense pubescence. Mentum ca as wide as long, subquadrate, with deep v-shaped impression anteromedially, with coarse punctures and wrinkles posteriorly (Fig. 5). Submentum with a small glabrous area medially and with a few coarse punctures laterally. Maxilla with coarse punctures, smooth between punctures.

Thorax. Pronotum ca $2 \times$ as wide as long, widest posteriorly, posterolateral margins broadly round, anterior margin smooth, with a very fine transverse groove, lateral margin with stronger groove, posterior margin without such groove; posterior margin almost straight. Ground punctures slightly coarser than those on head, systematic punctures on pronotum distinct, almost of same size as ground punctures (Figs 4, 6). Prosternum bulging in middle, not carinate, pubescent, with transverse groove (Fig. 5), protruding anteriorly. Mesoventrite with a low transverse ridge medially, which does not bear an elevated tooth or projection but with long setae (Fig. 7); behind ridge with a low longitudinal carina. Metaventrite pubescent, with somewhat convex middle portion, without glabrous area. Metepisterna ca $3.5 \times$ as long as wide, subparallel. Scutellum triangular, with similar punctures to elytra. Elytra almost parallel from base to posterior third, somewhat explanate laterally, ground punctures similar to those on pronotum, with 3 distinct rows of systematic punctures (Fig. 3), without sutural stria; epipleuron very broad anteriorly, reaching posterior margin of first visible abdominal sternite, with sparse, coarse punctures. Femora densely pubescent, with apical eighth glabrous (Figs 2, 8). Metatarsomeres with dense white hairs ventrally and a few long swimming hairs dorsally. Claws of moderate size, rather strongly curved.

ABdomen. All visible abdominal ventrites with dense pubescence; first ventrite not carinate (Figs 2, 8).

Aedeagus. Slender, length of parameres ca $10 \times$ as long as width of apex, subparallel, a little expanded subapically and round apically (Fig. 48), apex with a small, inwardly directed tooth (Figs 48-49); median lobe slightly protruding beyond parameres, gradually narrowed apically, apex ca $0.5 \times$ as wide as apex of parameres; basal strut long, ca $1 / 3 \times$ as long as parameres (Fig. 48).

\section{Differential diagnosis}

This species is very similar to H. fuliginosus d'Orchymont, 1932, but may easily be distinguished from the latter by its larger size (3.6-4.3 $\mathrm{mm}$ in $H$. fuliginosus), lateral margin of clypeus and elytra with same colour as disc (Fig. 4), pronotum and elytra more coarsely punctate, and maxillary palps dark 

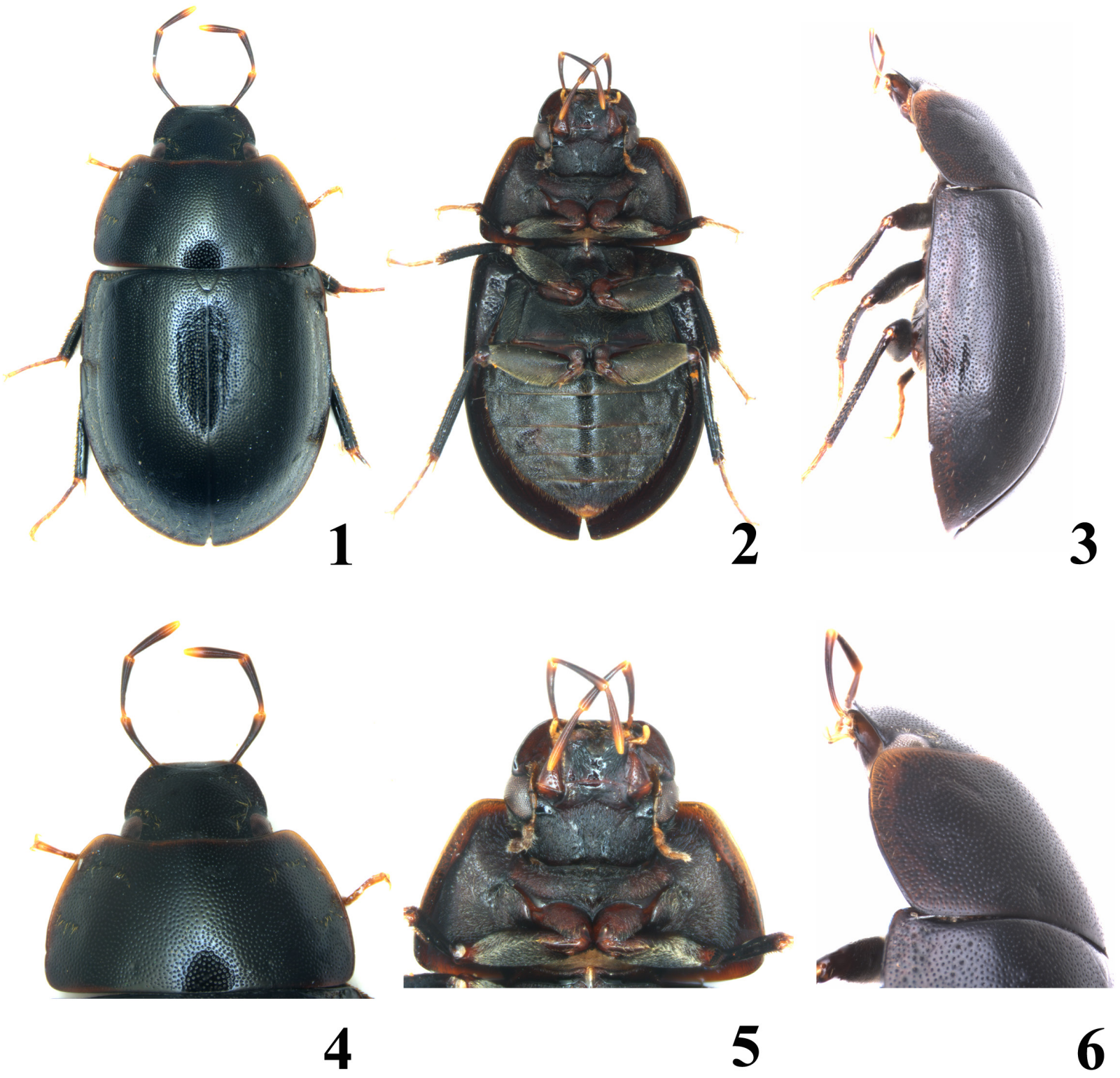

5
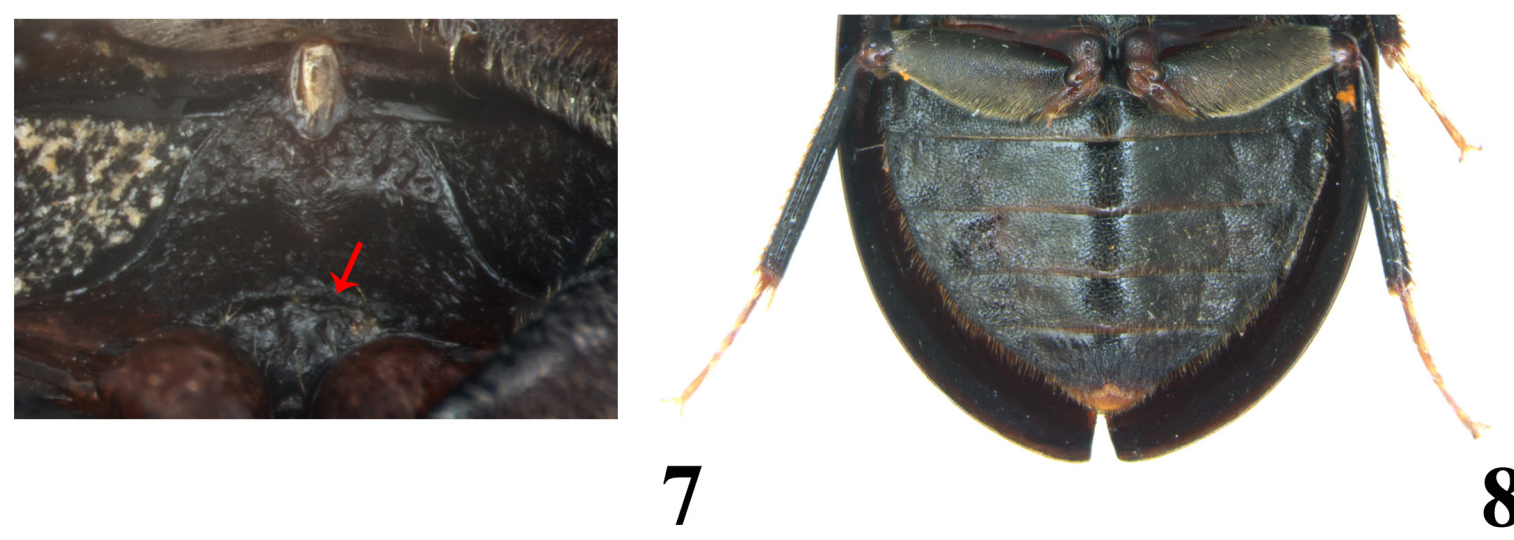

Figs 1-8. Helochares songi sp. nov. 1-3. Habitus. 1. Dorsal. 2. Ventral. 3. Lateral. 4. Head and pronotum. 5. Head and prosternum. 6. Pronotum, lateral. 7. Mesoventrite. 8. Abdomen. 
brown or black, each palpomere with light colour apically (Figs 4-5). Aedeagus slender, parameres ca $10 \times$ as long as width of apex (Fig. 48), apex with a small inwardly directed tooth (Figs 48-49); median lobe slightly projecting beyond parameres apically (Fig. 48). It can be distinguished from H. atropiceus Régimbart, 1903, H. ciniensis Hebauer, 1999 and H. taprobanicus Sharp, 1890, occurring in the Oriental, by its slender aedeagus, parameres ca $10 \times$ as long as width of apex, without branches, not concave outside, apex with a small inwardly directed tooth (Figs 48-49). Hebauer (1995) described Helochares fulgurans based on a unique female from Thailand. Helochares songi sp. nov. can be distinguished from $H$. fulgurans by its larger size (3.5 $\mathrm{mm}$ in $H$. fulgurans), dark colour (bright yellow brown, only dark between eyes, with two dark basal spots on pronotum in H. fulgurans) and maxillary palps dark brown or black, each palpomere with light colour apically (yellow in H. fulgurans). From H. vitalisi d'Orchymont, 1919 (Fig. 45) it differs in having the head, pronotum and elytra with coarser punctures (ground punctures very fine in $H$. vitalisi), each maxillary palpomere with light colour apically, clypeus moderately expanded laterally, with somewhat rounded lateral margin, clearly impressed in front of eyes (clypeus not expanded laterally and not impressed in front of eyes in $H$. vitalisi) and elytra almost parallel from base to posterior third (widest at middle in $H$. vitalisi), somewhat explanate laterally (not explanate in H. vitalisi, as in Enochrus).

\section{Biology}

Lives along the sides of rivers with a sandy bottom and stagnant water. The female carries the egg case under the abdominal ventrites.

\section{Remarks}

The density is very high at the type locality, but no specimen was collected at light in July. It is probable that this species can be collected at light during its reproductive period.

\section{Distribution}

China (Guangxi), so far only known from the Shiwandashan National Park and its surroundings.

Helochares fuliginosus d'Orchymont, 1932

Figs 9-17, 44, 46-47

Helochares (s. str.) fuliginosus d'Orchymont, 1932: 689.

\section{Diagnosis}

Length 3.6-4.3 mm. Dorsum with dense and fine punctures that are finer than in $H$. songi sp. nov. Clypeus somewhat impressed in front of eyes (Figs 12,14). Maxillary palps ca $1.2 \times$ as long as width of head, each palpomere uniformly yellowish brown (Figs 13-14). Pedicel subequal in length to antennomeres 3-6 combined. Submentum with a small glabrous area medially and with a few coarse punctures laterally (Fig. 16). Elytra almost parallel from base to posterior third, somewhat explanate laterally, with distinct systematic punctures (Fig. 9). Mesoventrite with a low transverse ridge medially and a low longitudinal carina (Fig. 15). Metaventrite without glabrous area medially. Femora densely pubescent except apical eighth (Figs 10,17). Length of parameres ca $6.5 \times$ as long as width of apex, subparallel, slightly expanded subapically and round apically, apex without inwardly directed tooth; median lobe expanded subapically, abruptly narrowed apically (Fig. 47).

\section{Material examined}

Paratype

JAVA: 1 Oे, Buitenzorg, “Bot. Gart. Quellmorast, 13. 1928," Exp. Thienemann leg., A. d'Orchymont det. (handwritten) (IRSN). 


\section{Other material}

LAOS: 1 + , Hua Phan Province, Ban Saluei Phu Phan Mt. Env., 20¹3' N, 1035' E, 1300-2000 m a.s.1., 6-18 Apr. 2004, J. Bezdek leg., Hebauer det. (NMPC).

CHINA: Guangdong: $6 \widehat{\partial} \widehat{\partial}, 9$ $q$, Z Zhaoqing, Heishiding, 4-6 May. 2013, Fenglong Jia, Yue Jia, Bingjie Chen, Renchao Lin and Weilin Xu leg.; 74 spec., Fengkai, Heishiding, $23^{\circ} 31^{\prime} \mathrm{N}, 111^{\circ} 52^{\prime} \mathrm{E}, 20$ 22 Apr. 2014, Fenglong Jia, Renchao Lin and Yudan Tang leg.; 1 spec., Fengkai, Heishiding, in a shallow puddle with plenty of leaf litter, 13 Aug. 2010, Fenglong Jia leg.; 1 spec., Gaoming, Yangmei town, 23-26 Apr. 2006, Fenglong Jia leg.; 37 spec., Zhuhai, Sun Yat-sen Univerisity, near mountain behind campus, 5-8 Jul. 2011, Fenglong Jia leg.; 46 spec., Shenzhen, Maluanshan, 13 Jun. 2014, Fenglong Jia and Weicai Xie leg.; 10 spec., Shenzhen, Wutongshan, Hengpailing, 15 May. 2011, Fenglong Jia leg.; 2 spec., Shenzhen, Paiyashan, 17 May 2011, Fenglong Jia leg.; 1 spec., Shenzhen, Qiniangshan, 17 Jun. 2010, Fenglong Jia leg.; 8 spec., Danxiashan, 8 Jun. 2012, light trap, Fenglong Jia leg.; 3 unsexed spec., Danxiashan, 2 May. 2008, Fenglong and Keqing Song leg.; 6 spec., Luogang, 20 Apr. 1958, Zhelong Pu leg. - Hong Kong: $2 \lesssim ふ, 1$ क , Shuikou, 27 Apr. 2013, Fenglong Jia, Yingming Lee and Eric Chen leg.; 4 spec., Dabujiao, 27 Apr. 2013, Fenglong Jia, Yingming Lee and Eric Chen leg.; 1 spec., Fengkeng, $22^{\circ} 31.695^{\prime} \mathrm{N}, 114^{\circ} 13.450^{\prime} \mathrm{E}, 13 \mathrm{~m}$ a.s.l., 9 Jun. 2014, Fenglong Jia, Weicai Xie and Jiahuang Chen leg.; 1 spec., Rongshuao, $22^{\circ} 32.646^{\prime} \mathrm{N}, 114^{\circ} 14.926^{\prime} \mathrm{E}, 10 \mathrm{~m}$ a.s.l., Fenglong Jia, Weicai Xie and Jiahuang Chen leg. - Fujian: 1 spec., Nanjing, Hexi town pond, 13 Jul. 2013, Fenglong Jia leg. - Guangxi: 1 , Shiwandashan, 8-12 Apr. 2013, Haidong Chen leg.; 1 spec., Shiwandashan, Forest Park, 239 m a.s.l., edge of upper river, 19 Jul. 2011, Keqing Song leg. - Macao: 3 spec., Luhuan, Dieshitang, 27 Mar. 2014, Fenglong Jia leg. [All data transcribed from Chinese.]

\section{Redescription}

FORM AND COLOUR. Length 3.6-4.3 mm, width 1.9-2.2 mm, oval, moderately convex. Head black, yellowish brown laterally (Figs 12-14); pronotum and elytra dark brown to black, both with yellowish or reddish brown margin laterally (Fig. 11); maxillary palps uniform yellow or yellowish brown (Figs 13-14); labial palps yellow, antenna yellowish brown. Ventral side dark brown to black (Fig. 10); legs dark with yellowish tarsomeres (Fig. 11).

HEAD. Labrum with fine and dense punctures, smooth between punctures, anterior margin broadly emarginate. Clypeus broad, anterior margin clearly broadly emarginate, moderately expanded in front of eyes, lateral margin somewhat rounded, clearly impressed in front of eyes (Figs 12-14). Punctures on clypeus coarser and sparser than those on labrum, smooth between punctures, systematic punctures almost of same size as ground punctures (Fig. 14). Eyes of moderate size, clearly emarginate anteriorly (Figs 12-14), separated by ca $4.0 \times$ the width of one eye. Ground punctures on frons similar to those on clypeus, with clear systematic punctures in front of eyes. Maxillary palps long and slender, ca $1.2 \times$ as wide as head, second and third palpomeres curved inwards, apical palpomere almost as long as penultimate, asymmetrical (Fig. 16). Antennae with 9 antennomeres, scape ca $1.5 \times$ as long as pedicel, pedicel subequal in length to antennomeres 3-6 combined, club loosely with dense pubescence. Mentum ca as wide as long, subquadrate, with strong v-shaped impression anteromedially, with coarse punctures and wrinkles posteriorly (Fig. 16). Submentum with a small glabrous area medially and with a few coarse punctures laterally. Maxilla with coarse punctures, smooth between punctures.

Thorax. Pronotum ca $2 \times$ as wide as long, widest posteriorly, posterolateral margins broadly round, anterior margin smooth, with a very fine transverse groove, lateral margin with stronger groove, posterior margin without such groove; posterior margin almost straight. Ground punctures on pronotum slightly coarser than on head, with distinct setiferous systematic punctures (Fig. 13). Prosternum bulging in middle, not carinate, pubescent, with transverse groove (Fig. 16), protruding anteriorly. Mesoventrite with a low transverse ridge medially, which does not bear an elevated tooth or projection but with 

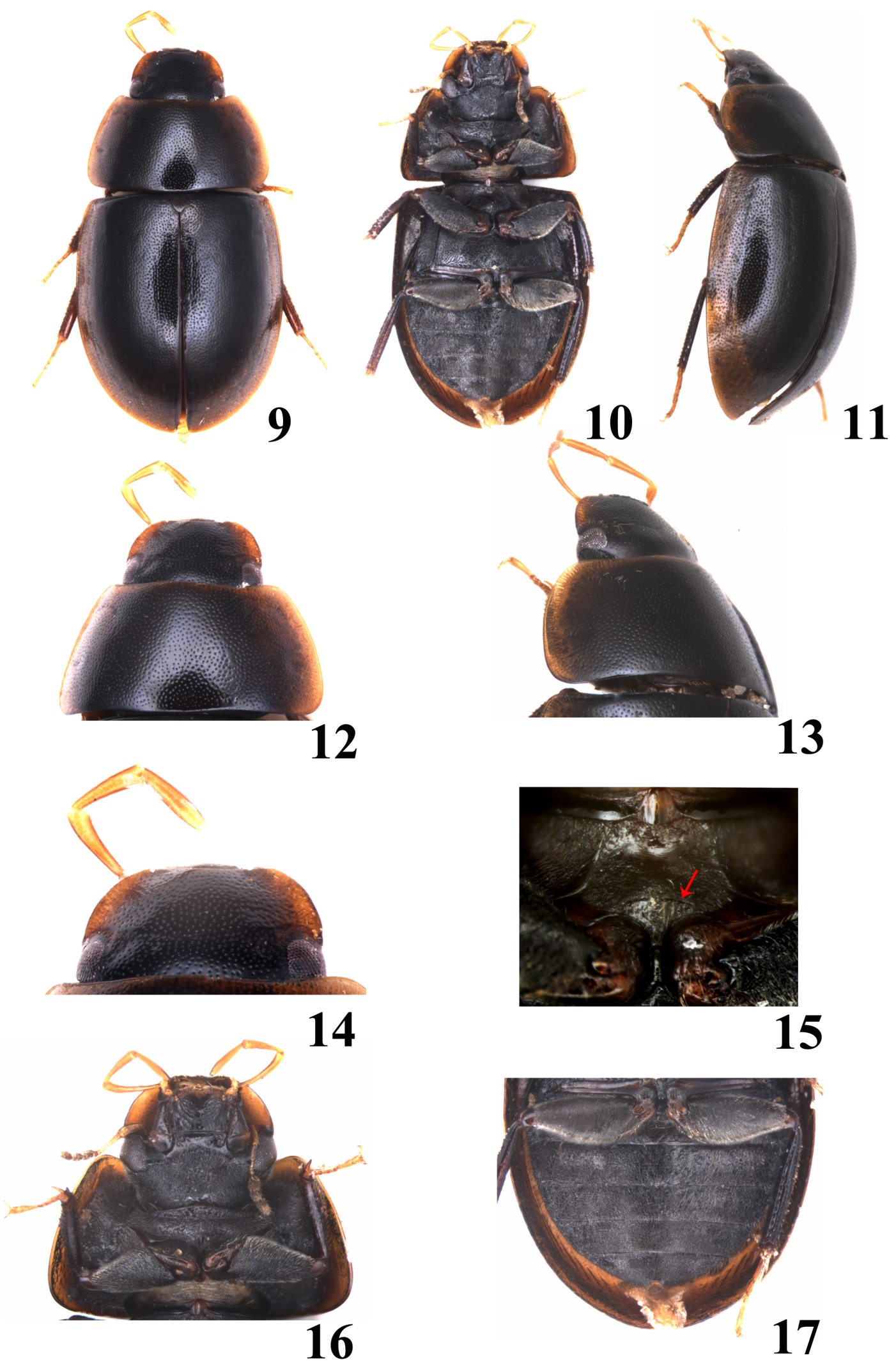

Figs 9-17. Helochares fuliginosus d'Orchymont, 1932.9-11. Habitus. 9. Dorsal. 10. Ventral. 11. Lateral. 12-13. Head and pronotum. 12. Dorsal. 13. Dorsolateral. 14. Head, dorsal. 15. Mesoventrite. 16. Head and prosternum. 17. Abdomen. 
a tuft of long setae (Fig. 15), behind ridge with a low longitudinal carina. Metaventrite pubescent, with somewhat convex middle portion, without glabrous area. Metepisterna ca $3.5 \times$ as long as wide, subparallel. Scutellum triangular, with similar punctures to elytra. Elytra with ground punctures similar to those on pronotum and with 3 distinct rows of systematic punctures (Fig. 11), without sutural stria; epipleura very broad anteriorly, reaching posterior margin of first visible abdominal sternite, with sparse, coarse punctures. Femora densely pubescent, with apical eighth glabrous (Figs 10, 17). Metatarsomeres with dense white hairs ventrally and some long swimming hairs dorsally. Claws of moderate size, rather strongly curved.

Aвdomen. All visible abdominal ventrites with dense pubescence; first ventrite not carinate (Fig. 17).

AEDEAGUs. Broad, paramere ca $6.5 \times$ as long as width of apex, subparallel, slightly expanded subapically and round apically, apex without small, inwardly directed tooth; median lobe somewhat expanded subapically, abruptly narrowed apically (Fig. 47).

\section{Differential diagnosis}

This species is closest to $H$. songi sp. nov., from which it can easily be distinguished by its smaller size; clypeus yellowish brown laterally (Fig. 12-14); elytra with yellowish or reddish brown margin laterally (Fig. 11); maxillary palps uniform yellow or yellowish brown (Figs 13-14); pronotum and elytra more finely punctate; parameres ca $6.5 \times$ as long as width of apex, apex without a small, inwardly directed tooth (Fig. 47).

\section{Biology}

This species occurs in small stagnant pools and on wet stones on ground with grass or leaf litter near rivers or streams, but never collected in habitats where Oocyclus spp. occur. It is occasionally collected at light. The female carries the egg case under the abdominal ventrites.

\section{Distribution}

China (Fujian, Guangdong, Guangxi, Hong Kong, Macau), Cambodia, Indonesia (Java, Sumatra), Malaysia (peninsula) (Hansen 1999). New record for China and Cambodia.

Helochares atropiceus Régimbart, 1903

Figs 18-25, 50-51

Helochares (s. str.) atropiceus Régimbart, 1903: 53 (specific rank confirmed by Hebauer 2001: 11; not a synonym of H. taprobanicus Sharp, 1890, as in Hansen 1999: 163).

Helochares (Helochares) ohkurai Satô, 1976: 21 (synonymyzed by Hebauer 2001: 11).

\section{Diagnosis}

Size 5.4-6.7 mm. Dorsum with distinctly sparser and finer punctures than in H. songi sp. nov. (Fig. 18). Labrum and clypeus with distinct systematic punctures. Clypeus never impressed in front of eyes (Figs 20-21). Eyes not emarginate anteriorly (Figs 20-21). Maxillary palpi ca $1.6 \times$ as long as width of head, each palpomere uniformly yellowish brown (Figs 18, 21). Antennae with pedicel distinctly shorter than antennomeres 3-6 combined. Submentum without a small glabrous area medially and with even, dense, coarse and strong punctures except extreme posterior portion (Fig. 22). Pronotum and elytra finely punctate. Mesoventrite with a stout, backwardly pointing projection, rising to level of mesocoxae, apex of the projection with a few long setae (Fig. 24). Metaventrite without glabrous area medially. Femora densely pubescent except apical eighth (Figs 19,25). Parameres somewhat wider than widest part of median lobe, each paramere with 3 branches: inner branch short and strongly curved inwards; median branch knife-formed, sharp apically, slightly longer than outer branch; outer branch narrower 
than other two branches, apical third curved inwards, sharp apically. Median lobe with broad basal half, gradually narrowed apically. Basal strut very short (Figs 50-51).

\section{Material examined}

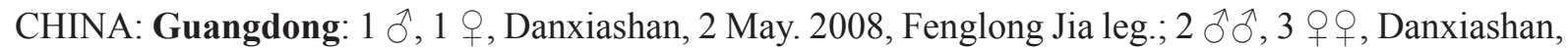
8 Jun. 2009, Fenglong Jia leg.; 1 spec., Shaoguan, Danxiashan, 27 May. 2010, Fenglong Jia leg.; 1 spec., Danxiashan, 21 Jul. 2011, Shuang Zhao leg.; 1 spec., Shaoguan, Danxiashan, 21 Apr. 2012, Haidong Chen leg.; 6 spec., Danxiashan, 23-26 Apr. 2013, Fenglong Jia, Shuang Zhao, Weicai Xie and Haidong Chen leg.; 3 spec., Danxiashan nursery, 8 Jun. 2012, light trap, Fenglong Jia leg.; 2 spec., Danxiashan, Yangyuanshan, 10 Apr. 2011, Fenglong Jia leg.; 1 spec., Zhuhai, campus of Sun Yat-sen University, 5-8 Jul. 2011, Fenglong Jia leg.; 1 spec., Fengkai, Heishiding, 3 Jun. 2011, light trap, Fenglong Jia leg.; 1 spec., Heshan, 22-24 Apr. 2002, Haidong Chen leg.; 1 spec., Heyuan, Wanlvhu, 15-17 Aug. 2005, Shuang Zhao leg.; 1 spec., Shenzhen, Longgang, 23-25 May 2011, Fenglong Jia leg.; 1 spec., Shenzhen, Neilingding, 4 Jul. 1998, Haidong Chen leg. - Hong Kong: 2 ㅇ, 3 웅, 34 spec., Qingkuaitang, 29 Oct. 2013, light trap, Y.M. Lee, Eric Chen and Alex Lee leg.; 9 spec., Fengkeng, 22 ${ }^{\circ} 31.695^{\prime}$ N, $114^{\circ} 13.450^{\prime}$ E, 13 m a.s.1., 9 Jun. 2014, Fenglong Jia, Weicai Xie and Huangjia Chen leg.; 7 spec., Dabujiao (Hexi), $22^{\circ} 25.697^{\prime} \mathrm{N}, 114^{\circ} 10.834^{\prime}$ E, $144 \mathrm{~m}$ a.s.1., 10 Apr. 2014, Fenglong Jia, Weicai Xie and Huangjia Chen leg.; 2 spec., Rongshu'ao, $22^{\circ} 32.646^{\prime}$ N, $114^{\circ} 14.926^{\prime}$ E, 10 m a.s.1., 11 Apr. 2014, Fenglong Jia, Weicai Xie and Huangjia Chen leg. - Guangxi: 1 spec., Shiwandashan forest park, $263 \mathrm{~m}$ a.s.1., 7 Jul. 2011, light trap, Keqing Song leg. (English label); 2 spec., Shiwandashan forest park, 263 m a.s.1., 7 Jul. 2011, light trap, Keqing Song leg. (transcribed from Chinese); 1 spec., Shiwandashan, 8-12 Apr. 2013, Haidong Chen leg. (English labels). - Guizhou: 1 ô, 1 ㅇ, Yaoshan, 25 May 1938. Jiangxi: 1 đ̆, Jiulianshan, Daqiutian, 31 Aug. 2007, light trap, Hong Pang leg. - Macao: 1 q, Ludang city, ecological reserve, section one, 9 May 2013, Weicai Xie leg. [All data transcribed from Chinese, unless otherwise specified.]

\section{Redescription}

Form AND COLOUR. Body length 5.4-6.7 mm, width 3.2-3.7 mm, oval, moderately convex. Head uniformly black (Figs 18,21); pronotum dark brown to black, usually narrowly reddish brown laterally, posterior margins usually yellow brown laterally (Figs 21,23), elytra black, with reddish brown lateral margins (Fig. 20); antennae, maxillary and labial palps uniformly reddish or yellowish brown (Figs 18, 21). Ventral side dark brown to black, legs dark with reddish brown tarsomeres (Figs 19, 24). Immatures with reddish brown pronotum and elytra and dark brown head.

HEAD. Labrum with fine and dense punctures, smooth between punctures, with distinct systematic punctures, anterior margin broadly emarginate. Clypeus broad, with coarser and sparser punctures than those on labrum, smooth between punctures, systematic punctures distinct; anterior margin clearly emarginate, at most slightly expanded in front of eyes, never impressed in front of eyes (Figs 20-21). Eyes of moderate size, not emarginate anteriorly (Figs 20-21), separated by ca $4.0 \times$ the width of one eye. Frons with as coarse and strong punctures as clypeus, with clear systematic punctures. Maxillary palps long and slender, ca $1.6 \times$ as wide as head, second and third palpomeres curved inwards, apical palpomere ca $0.85 \times$ as long as penultimate, asymmetrical. Antennae with 9 antennomeres, scape ca $1.5 \times$ as long as pedicel, pedicel ca $2 / 3 \times$ as long as antennomeres $3-6$ combined, club loosely segmented with dense pubescence. Mentum ca as wide as long, subquadrate, with strong v-shaped impression anteromedially, with coarse punctures, with wrinkles posteriorly (Fig. 22). Submentum without a small glabrous area medially and with even, dense, coarse and strong punctures, smooth between punctures (Fig. 22). Maxilla with a few punctures that are finer than those on submentum (Fig. 22).

THorax. Pronotum ca $2 \times$ as wide as long, widest posteriorly, posterolateral margin broadly round, anterior and posterior margins smooth, with a very fine transverse groove, lateral margin with stronger 

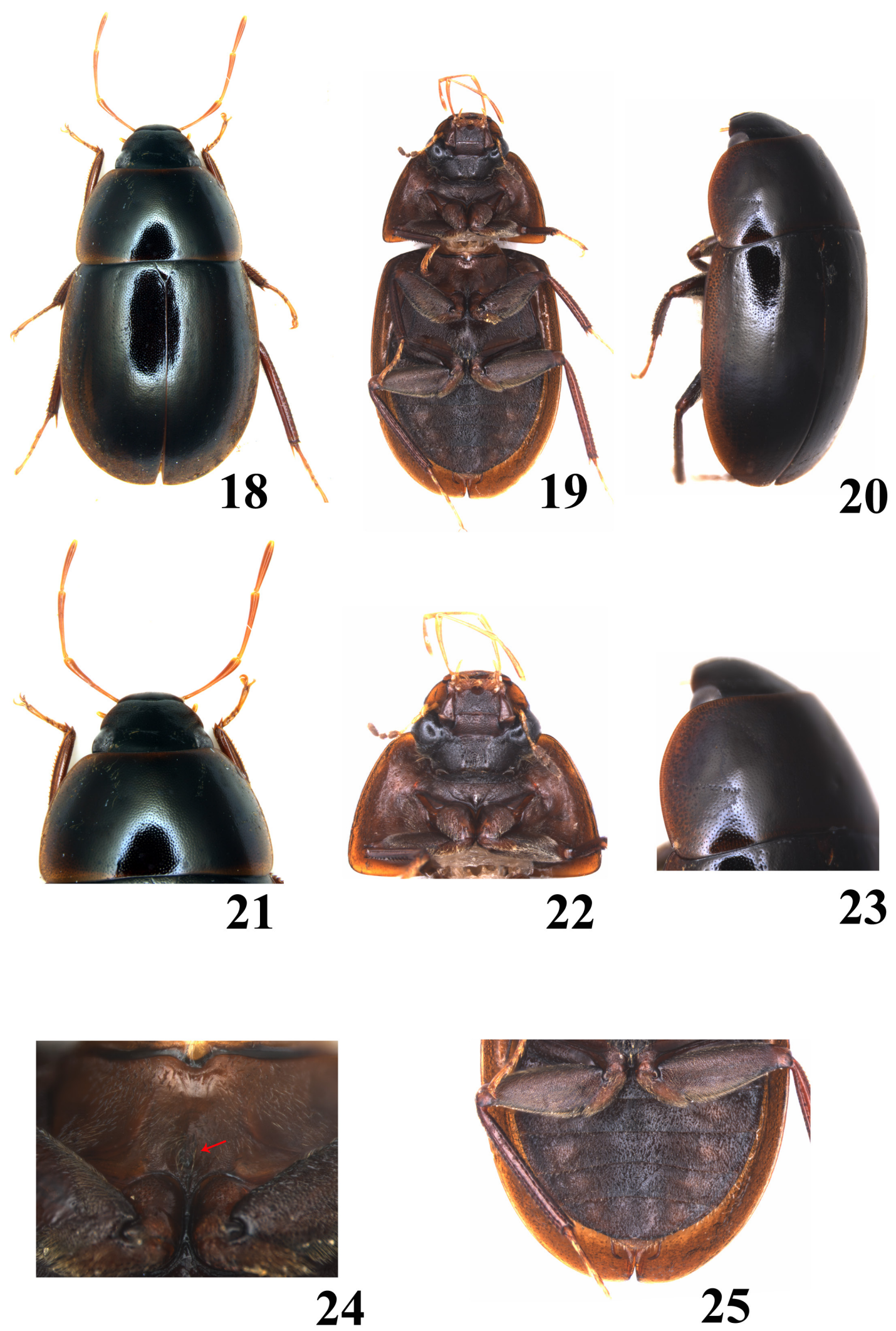

Figs 18-25. Helochares atropiceus Régimbart, 1903. 18-20. Habitus. 18. Dorsal. 19. Ventral. 20. Lateral. 21. Head and pronotum. 22. Head and prosternum. 23. Pronotum, dorsolateral. 24. Mesoventrite. 25. Abdomen. 
groove; posterior margin slightly bisinuate, with median portion widely curved, punctures slightly coarser than those on head, with distinct setiferous systematic punctures (Figs 20-21, 23). Prosternum bulging in middle, not carinate, pubescent, with transverse groove, protruding anteriorly (Fig. 22). Mesoventrite with a stout, backwardly pointing projection, rising to level of mesocoxae, apex of projection with a few long setae (Fig. 24). Metaventrite without glabrous area medially; metepisterna ca $3.5 \times$ as long as wide, subparallel. Scutellum triangular, with similar punctures to those on elytra. Ground punctures on elytra similar to those on pronotum and clearly with three distinct rows of systematic punctures (Fig. 20); epipleura very broad anteriorly, reaching posterior margin of first visible abdominal sternite, with sparse, coarse punctures. Femora densely pubescent with apical eighth glabrous (Figs 19, 25). Metatarsomeres with dense golden hairs ventrally and some long swimming hairs dorsally. Claws of moderate size, rather strongly curved.

Aвdomen. All visible abdominal ventrites with dense pubescence; first ventrite not carinate (Fig. 25).

Aedeagus. Very broad. Parameres somewhat wider than widest part of median lobe, each paramere with 3 branches: inner branch short and strongly curved inwards; median branch knife-formed, sharp apically, almost as long as outer branch; outer branch narrower than other two branches, apical third curved inwards, sharp apically. Median lobe with broad basal half, gradually narrowed apically. Basal strut very short (Figs 50-51).

\section{Differential diagnosis}

It is very easy to distinguish this species from other species known from China by its large size, dark brown to black colour, pronotum and elytra finely punctate, mesoventrite with a stout, backwardly pointing projection, rising to the level of the mesocoxae, the apex of the projection with a few long setae, each paramere with 3 branches. For the differences between $H$. atropiceus and allied species, see Hebauer (2001).

\section{Biology}

Living in natural ponds with leaf litter or water grass, can sometimes be collected on wet ground with plenty of grass. It can be collected at light in May and June in South China. It has never been collected from the edges of rivers and streams. The female carries the egg case under the abdominal ventrites.

\section{Distribution}

China (Guangdong, Guangxi, Guizhou, Hong Kong, Jiangxi, Macau), Bangladesh, Japan (Ryukyu Islands), Malaysia, Nepal, Thailand, Vietnam (Fikáček et al. 2015; Hansen 1999). New record for Guizhou, Hong Kong and Macau.

Helochares obscurus (Müller, 1776)

Figs 26-31, 53-55

Hydrophilus obscurus Müller, 1776: 69.

Hydrophilus erythrocephalus Fabricius, 1792: 185.

Hydrophilus variegatus var. variegatus Herbst, 1797: 304.

Helochares subcompressus Rey, 1885: 14.

Helochares erythrocephalus var. substriatus Sahlberg, 1913: 20.

Helochares griseus a. Mülleri Reitter, 1909: 364.

Hydrophilus griseus var. variegatus - Gyllenhal 1808: 122.

Helophilus lividus var. erythrocephalus - Mulsant 1844: 135.

Philhydrus lividus var. erythrocephalus - Gemminger \& Harold 1868: 481. 
Philhydrus lividus var. variegatus - Gemminger \& Harold 1868: 481.

Helochares (i. sp.) erythrocephalus - Kuwert 1890: 37.

Helochares (s. str.) griseus var. substriatus - Zaitzev 1908: 382.

Helochares (s. str.) obscuus - d'Orchymont 1933: 306.

\section{Diagnosis}

Length 5.0-6.4 mm. Yellowish brown to reddish brown with dark head (Fig. 26). Dorsum with dense and coarse punctures. Systematic punctures on clypeus of the same size as ground punctures. Clypeus never impressed in front of eyes (Fig. 28), lateral margin distinct narrowed anteriorly. Eyes somewhat emarginate anteriorly (Fig. 28). Maxillary palps yellowish brown with infuscate apex (Figs 28-29), ca $1.3 \times$ as long as width of head. Antennae with pedicel slightly shorter than antennomeres 3-6 combined. Submentum with small glabrous areas medially and with uneven, dense, coarse and strong punctures (Fig. 29). Elytra usually with some longitudinal rows of black spots (Fig. 26), systematic punctures on pronotum and elytra indistinct (Figs 26, 28). Mesoventrite with a low transverse ridge medially, which does not bear an elevated tooth or projection but with a tuft of long setae (Fig. 30). Metaventrite without glabrous area medially. Femora densely pubescent except apical eighth (Figs 27, 31). Aedeagus (Figs 53-55) ca $2.4 \times$ as long as wide. Apex of paramere dilated inwards, rounded near apex, not distinctly angular (dorsal view). Membranous inner sac with several small dentiform bulges on each side, corresponding to a number of sclerotized spines of median lobe that are visible when the median lobe is extended.

\section{Material examined}

CHINA: Xinjiang: 1 đ, Tacheng, Haerdun River dike, 4 Aug. 2005, Ling Zhao leg.; 1 , Yining, Yili River, 5 Aug. 1984, Zhihe Huang leg.

\section{Redescription}

FORM AND COLOUR. Body length 5.0-6.4 mm, width 2.4-3.1 mm, oval, moderately convex. Head yellowish to dark brown, labrum dark brown or black. Pronotum yellowish to reddish brown (Figs 26, 28). Elytra with same colour as pronotum but with some longitudinal rows of black spots (Fig. 26). Maxillary palps yellowish brown with last palpomere black apically (Figs 28-29). Antennae yellowish brown with somewhat dark club. Labial palps reddish or yellowish brown and dark apically (Figs 27-28). Ventral side dark brown, legs with apices of femora, tibiae and tarsomeres yellowish brown (Fig. 27).

Head. Labrum with fine punctures, systematic punctures detectable. Clypeus broad, anterior margin broadly emarginate, lightly expanded in front of eyes, not impressed in front of eyes (Fig. 28), with moderately coarse and dense punctures, systematic punctures of same size as ground punctures (Fig. 28). Eyes moderate in size, emarginate anteriorly; interval between eyes ca $4 \times$ as wide as one eye. Ground punctures on frons similar to those on clypeus, systematic punctures only slightly coarser than ground punctures. Maxillary palps long and slender, ca $1.3 \times$ as long as width of head, $1^{\text {st }}$ and $2^{\text {nd }}$ palpomeres curved inwards, apical palpomere a little shorter than penultimate, slightly bending inwards. Antennae with 9 antennomeres, scape ca $1.5 \times$ as long as pedicel, pedicel almost as long as antennomeres 3-6 combined, club loosely segmented, bearing dense pubescence (Figs 27, 29). Mentum ca $1.3 \times$ as wide as long, subquadrate, moderately impressed anteromedially, with coarse punctures and wrinkles (Fig. 29). Submentum with uneven, coarse punctures and small, glabrous areas medially (Fig. 29).

THORAX. Pronotum ca $2 \times$ as wide as long, widest medially; anterior margin and posterior margin almost straight; with punctures as on head, systematic punctures arranged as two transverse oblique rows, almost of same size as ground punctures (Fig. 28). Prosternum bulging in middle, not carinate, with transverse groove, protruding anteriorly. Mesoventrite with a low transverse ridge medially, which does not bear 


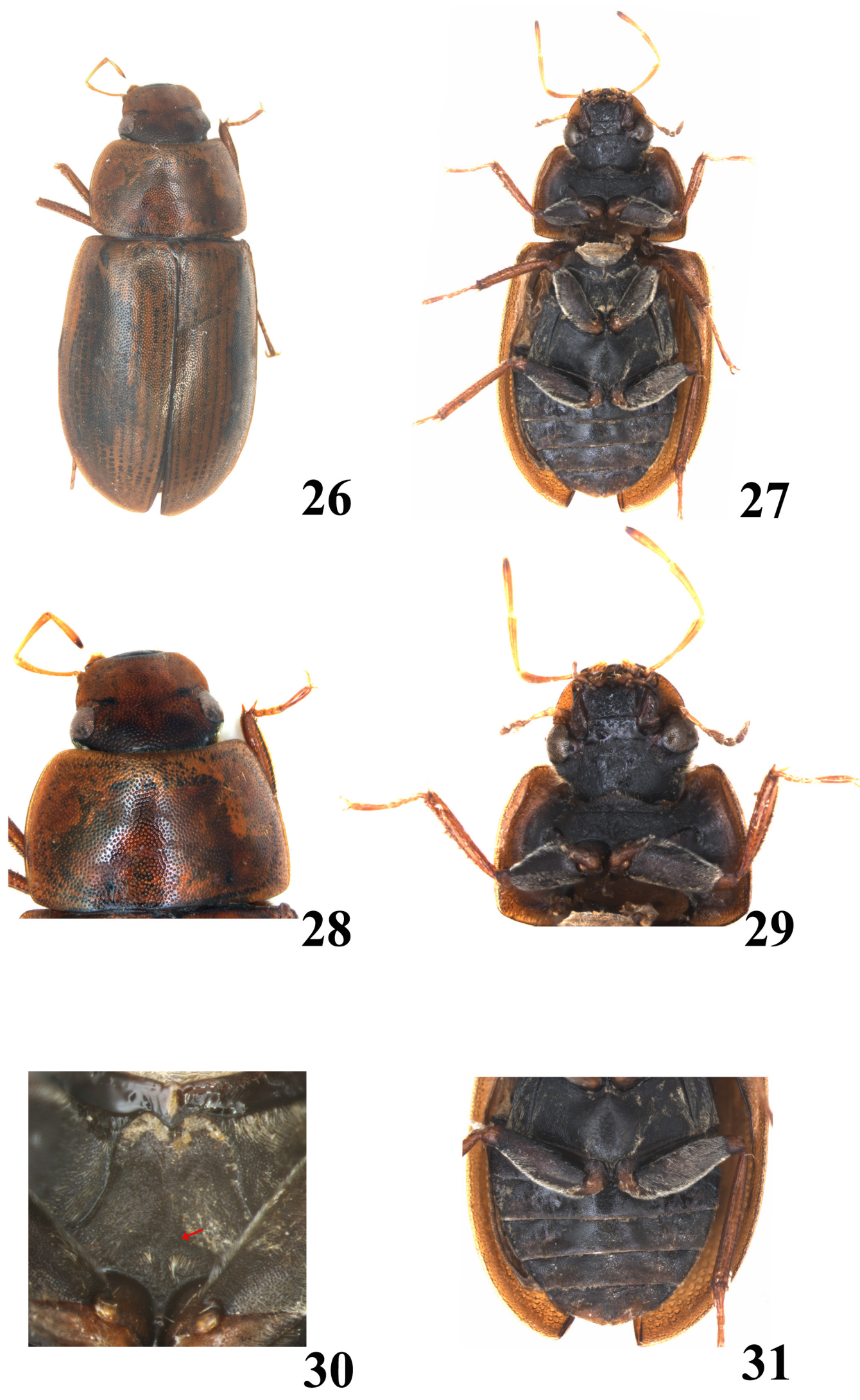

Figs 26-31. Helochares obscurus (Müller, 1776). 26-27. Habitus. 26. Dorsal. 27. Ventral. 28. Head and pronotum. 29. Head and prosternum. 30. Mesoventrite. 31. Abdomen. 
an elevated tooth or projection but with a tuft of long setae, behind the ridge, with a low, longitudinal carina between mesocoxae (Fig. 30). Metaventrite pubescent, with somewhat convex middle portion, without glabrous area; metepisterna ca $3.5 \times$ as long as wide, subparallel. Scutellum triangular, with similar punctures to those on elytra. Ground punctures on elytra similar to those on pronotum, with 2 or 3 rows of indistinct systematic punctures (Fig. 26). Epipleura very wide anteriorly, gradually narrowed, reaching level of first visible abdominal sternite. Femora densely pubescent with apical eighth glabrous. Metatarsomeres with dense white hairs ventrally and a few long swimming hairs dorsally. Claws of moderate size, rather strongly curved.

Aвdomen. All visible abdominal ventrites with dense pubescence; first ventrite not carinate (Fig. 31).

Aedengus. Ca $2.4 \times$ as long as wide. Apex of parameres dilated inwards, rounded near apex, not distinctly angular (dorsal view). Membranous inner sac with several small dentiform bulges on each side, corresponding to a number of sclerotized spines of median lobe, visible when median lobe is extended. Median lobe with spine-formed apex (Figs 53-55). Apex of median lobe of aedeagus (Fig. 53) damaged during our dissection of the unique male. We used the figures of Hansen (1987) here for illustration (Figs 54-55).

\section{Differential diagnosis}

This species can easily be distinguished from other species occurring in China by its having the pronotum and elytra yellow brown, head only dark between the eyes, elytra with some longitudinal rows of black spots, aedeagus with a membranous inner sac, median lobe with a number of sclerotized spines and with a spine-formed apex. For the differential characters between it and H. pallens (McLeay, 1825) see the Differential diagnosis of that species. This species is close to the Palaearctic H. punctatus Sharp, 1869. The differential characters were given by Hansen (1987).

\section{Remarks}

This species seems to live in water at the edge of dams and the margins of rivers. Other biological characters are unknown.

\section{Distribution}

China (Xinjiang); Palearctic: Austria, Azerbaijan, Belarus, Croatia, Czech Republic, Denmark, Estonia, Finland, France, Germany, Great Britain, Greece, Hungary, Iran, Israel, Italy, Kazakhstan, Latvia, Lithuania, Luxemburg, Montenegro, Netherlands, Norway, Poland, Russian Fed. (Russia, West Siberia), Slovakia, Sweden, Switzerland, Turkey, Ukraine (Fikáček et al. 2015; Hansen 1999).

Helochares pallens (MacLeay, 1825)

Figs 32-42, 52

Enhydrus pallens MacLeay, 1825: 35.

Helochares parvulus Reiche \& Saulcy in Reiche, 1854: 9.

Helochares lewisius Sharp, 1873: 60.

Helochares dispar Sharp, 1903: 7.

Helochares laeviusculus Régimbart, 1906: 261.

Helochares parvulus - Reiche \& Saulcy 1856: 359.

Philhydrus pallens - Gemminger \& Harold 1868: 482.

Philhydrus parvulus - Gemminger \& Harold 1868: 482.

Helochares (s. str.) lewisianus - Zaitzev 1908: 382 (misspelling).

Enochrus (Methydrus) parvulus - Zaitzev 1908: 384. 
Enochrus (Lumetus) pallens - Zaitzev 1908: 388.

Helochares (s. str.) pallens - d'Orchymont 1926: 232.

Helochares (s. str.) pallens ssp. laeviusculus - Balfour-Browne 1950: 60.

\section{Diagnosis}

Length 2.8-3.4 mm. Yellowish brown with labrum and frons dark (Fig. 32). Dorsum with finer punctures (Fig. 36). Systematic punctures on clypeus slightly stronger than ground punctures. Clypeus never impressed in front of eyes, lateral margin distinctly narrowed anteriorly (Figs 35-36). Maxillary palps yellowish brown, ca $1.2 \times$ as long as width of head. Antennae with pedicel slightly shorter than antennomeres 3-6 combined. Mentum slightly impressed anteromedially, never with wrinkles (Fig. 37). Submentum with somewhat even, dense, coarse and strong punctures. Usually eight to nine striae on underside of elytra visible from dorsal side (Figs 32, 41-42). Mesoventrite without a low transverse ridge medially (Fig. 39). Metaventrite without glabrous area medially. Femora densely pubescent except apical eighth. Apex of parameres not dilated inwards, somewhat narrowly rounded near apex. Membranous inner sac with several small dentiform bulges on each side. Median lobe with sharp apex (Fig. 52).

\section{Material examined}

CHINA: Guangdong: $3 \hat{\jmath} \widehat{\partial}, 2$ q $q, 28$ spec., Xuwen, 27 Apr. 1985, Zhihe Huang leg.; $2 \hat{\jmath}, 4$ 우, 34 spec., Lianjiang, 25 Apr. 1985, Wu Wu leg.; 2 우, Lianjiang, Shiling, 12 Apr. 1985, Zhihe Huang leg.; 1 \%, Shiling, 12 Apr. 1985, Wu Wu leg.; 1 ô, Lianjiang, Shiling, 24 Apr. 1985, Wu Wu leg.; 3 spec., Guangzhou, Aug. 1938, Zhelong Pu leg.; 12 spec., Guangzhou, Henan, 24 May 1957, Zhelong Pu leg.; 2 spec., Guangzhou, Henan, 1 Mar. 1958, Zhelong Pu leg.; 9 spec., "Hainan”, 17 Jul. 1957, Zhelong Pu leg.; 4 spec., "Hainan”, 16 Jul. 1957, Cuiying Li leg.; 2 spec., "Hainan”, 17 Jul. 1957, Cuiying Li leg.; 6 spec., Yingde, 5 Aug. 1962, Ping Lin leg.; 3 spec., Lechang, 12 Aug. 1962, Ping Lin leg.; 34 spec., Xinhui, Aug. 2001, Xiaoli Tong leg.; 8 spec., Xingning, Luofu Mount, Huangmao peak, 1 Jul. 2004, Fenglong Jia leg.; 2 spec., Xingning, Luofu Mount, Tieshan, 1 Jul. 2004, Fenglong Jia leg.; 6 spec., Lianzhou, Dadong Mount, 25-28 Jul. 2008, Yun Wang leg.; 16 spec., Fengkai, Heishiding, 3 Jun. 2001, light trap, Fenglong Jia leg.; 3 spec., Fengkai, Heishiding, 20-22 Apr. 2014, Fenglong Jia, Renchao Lin and Yudan Tang leg.; 3 spec., Fengkai, Heishiding, 2 Jul. 2011, Lijun Yang leg.; 2 spec., Fengkai, Heishiding, 10 Apr. 1985, Wu Wu leg.; 3 spec., Fengkai, He'erkou, 3 Jul. 2011, Lifeng Yang leg.; 2 spec., Fengkai, He'erkou town, 55 m a.s.l., 22 Apr. 2014, Fenglong Jia, Renchao Lin and Yudan Tang leg.; 8 spec., Guangzhou, Shuzhugang, 3 May 1957, Zhelong Pu leg.; 3 spec., Heshan, 18 Mar. 1994, Fenglong Jia leg.; 9 spec., Shipai, 5 Aug. 1956, Zhelong Pu leg.; 16 spec., Huaxian, Dapuling, 26 Aug. 1983, Zhihe Huang leg.; 2 spec., Raoping, summer of 1961; 46 spec., Danxia Mount, nursery, 8 Jun. 2012, Fenglong Jia leg.; 1 spec., Danxia, Yangyuan Mount, Huiyuan pool, 8 Jun. 2012, Fenglong Jia leg.; 5 spec., Danxia Mount, paddy field in the north of Yangyuanshi, 23 Apr. 2012, Fenglong Jia and Junlei Liao leg.; 1 spec., Danxia Mount, 23-26 Apr. 2013, Fenglong Jia leg.; 13 spec., Zhuhai, 24 Jun. 2011, Fenglong Jia leg.; 4 spec., Zhuhai, mountain behind campus of Sun Yat-sen University, 5-8 Jul. 2011, Fenglong Jia leg.; 6 spec., Zhuhai, Hengqing Island, 10 Jul. 2006, Fenglong Jia leg.; 6 spec., Zhuhai, Qi'ao Island, 13-15 Jul. 2005, Fenglong Jia leg.; 16 spec., Gaoming, Yangmei town, 23-26 Apr. 2006, Fenglong Jia leg.; 18 spec., Guangzhou, Lianhe, 18 May 1964, Jincai Bao and Zhenyao Chen leg.; 24 spec., Guangzhou, Baiyun Mount, 2 Jun. 1964, Jincai Bao leg.; 27 spec., Guangzhou, Xinshi, 11 May 1964, Chengmu Chen and Zhengwei Huang leg.; 19 spec., Guangzhou, Luhu Lake, 2 Jun. 1964, Zhenyao Chen leg.; 6 spec., Guangzhou, Shipai, 8 May 1964, Zhaojian Liang leg.; 2 spec., Guangzhou, Chisha, 28 Apr. 1964, Zhenyao Chen leg.; 6 spec., Heyuan, Wanlu Pool, 15-17 Aug. 2005, Shuang Zhao leg.; 5 spec., Ruyuan, Longxi, 9 May 1964, Zhenyao Chen leg.; 1 spec., Guangzhou, campus of Sun Yat-sen University, 16 May 1964, Jincai Bao leg.; 1 , Guangzhou, campus of Sun Yat-sen University, Jul. 1985; 1 spec., Guangzhou, Sun Yat-sen University, 20 Jun. 1958; 1 đ, Sihui, Dasha, 6 Mar. 1988, 
Fenglong Jia leg.; 7 spec., Shenzhen, Futian Mangrove, salt-water fish pond, 30 May-1 Jun. 2015, Fenglong Jia and Renchao Lin leg.; 2 $\jmath^{\lambda}, 2$ 웅, 17 spec., Shenzhen, Futian Mangrove, 2-4 Apr. 2015, Fenglong Jia, Renchao Lin, Zhenhua Liu and Kai Chen leg.; 6 spec., Shenzhen, Yapai Mount, 17 May 2012, Fenglong Jia and Junlei Liao leg.; 1 spec., Shenzhen, Nan'ao, 26 May 2011, Xiaodong Wang and Junlei Liao leg.; 1 9, Shenzhen, Haifeng Reservoir, 8-11 Aug. 2006, Fenglong Jia leg.; 1 spec., Shenzhen, Qiniang Mount, 7 Jun. 2010, Fenglong Jia leg.; 3 spec., Shenzhen, Longgang, 23-25 May 2011, Fenglong Jia leg.; 1 spec., Shenzhen, Neilingding, 3 Jul. 1998, Haidong Chen leg.; 4 spec., Zhanjiang, Chikan,

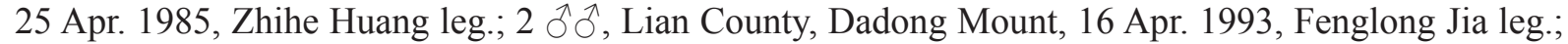
2 spec., Dinghu Mount, 17 Jul. 1964, Tongxu Peng leg.; 5 spec., Puning, 3 Jan. 1959, Zhelong Pu leg.; 6 spec., Puning, autumn 1958, Zhelong Pu leg.; 2 spec., Guangzhou, Kangle village, Apr. 1957, Ping Lin leg.; 1 spec., Shantou, 15 May 1964, Tongxu Peng leg.; 1 spec., Nanxiong, summer 1942, Zhelong Pu leg.; 1 spec., Dong town, 7 Jul. 1960, Zhelong Pu leg.; 1 spec., Xinyi, 7 Jun. 1960, Zhelong Pu leg.; 1 spec., Lian town, Jun. 1945, Zhelong Pu leg.; 1 spec., Qujiang, Guitou, autumn 1942, Mengyi Mo leg.

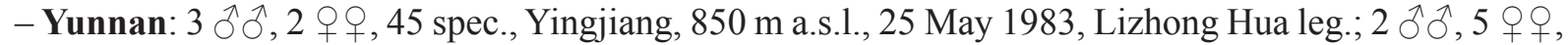
75 spec., Huijiang, 30 Apr. 1939, Zhelong Pu leg.; 11 spec., Chenggong, 24 Apr. 1940; 80 spec., Pohui, 2 Apr. 1939, Zhelong Pu leg.; 1 spec., Jinning, 24 Apr. 1940, Zhelong Pu leg.; 8 spec., Kunming, 28 May 1939, Zhelong Pu leg.; 8 spec., Lufeng village, 26 Mar. 1940, Zhelong Pu leg.; 2 spec., Lufeng village, 25 Jul. 1939, Zhelong Pu leg.; 3 spec., Pingyi, 1 May 1940, Zhelong Pu leg.; 1 spec., Nujiang Valley, 800 m a.s.1., 9 May 1955; 1 spec., Jinping, Mengla, 370 m a.s.1., 30 Apr. 1956, Renke Huang leg. -

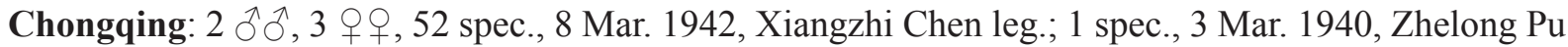
leg. - Sichuan: 2 spec., E'mei, 1 Aug. 1982, Zhihe Huang leg.; 1 spec., Fujiang, Qiongjiang County,

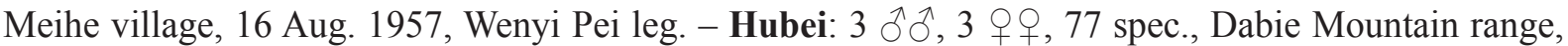
Qingtaiguan, $31^{\circ} 12.2^{\prime} \mathrm{N}, 115^{\circ} 42.1^{\prime} \mathrm{E}, 1-4$ Jul. 2014, Zhenhua Liu leg.; 2 spec., Dabie Mountain range, Wujia Mountain, $31^{\circ} 7.6^{\prime} \mathrm{N}, 115^{\circ} 45.1^{\prime}$ E, 29 Jun. 2014, light trap, Zhenhua Liu leg.; 4 spec., Wuchang, 17-19 May 1961, Zhelong Pu leg.; 1 spec., Wuchang, 19 May 1961, Zhelong Pu leg.; 1 spec., Zigui, Jiulingtou, 110 m a.s.1., 6 Apr. 1994, Fasheng Li leg. - Hunan: 1 ô, 2 q , Huaihua, 15 Aug. 1982, Zhihe Huang leg.; 5 spec., Huaihua, 17 Aug. 1982, Zhihe Huang leg.; 11 spec., Tongdao, 19 Aug. 1982, Zhihe Huang leg.; 4 spec., Tongdao, 20 Aug. 1982, Zhihe Huang leg.; 5 spec., Yizhang, 10 Feb. 1941, Zhelong Pu leg.; 6 spec.; Yizhang, 16 Mar. 1941, Zhelong Pu leg.; 24 spec., Yizhang, 1 Apr. 1942, Zhelong Pu leg.; 34 spec., Nanyue, 4 Apr. 1941, Zhelong Pu leg.; 7 spec., Hengshan, Jun. 1941, Zhelong Pu leg.; 3 spec., Qianyang, An'jiang, 20 Jun. 1965, Zhenyao Chen leg.; 2 spec., Xianghuaihua, Yushuwan, 17 Jun. 1965, Zhenyao Chen leg.; 3 spec., Zhuzhou City, Yanling County, Taoyuandong, Mihua village, 25 May 2014, Renchao Lin, Xiaolin Liu and Chang Pan leg. - Guangxi: 75 spec., Yangshuo, 1985, Shoujian Chen leg.; 37 spec., Hechi, 4 Jun. 1941, Zhelong Pu leg.; 13 spec., Nanning, 19-20 Jun. 1977, Zhihe Huang leg.; 3 spec., Longlin, 22 Mar. 1977, Zhihe Huang leg.; 5 spec., Shangsi County, Hualan village pond, 204 m a.s.1., 6. Jul. 2011, Keqing Song leg.; 1 spec., Jingxi, Bangliang, 6 Aug. 2010, Jianhua Huang leg. - Fujian: $2 \widehat{\jmath}, 8$ spec., Fuzhou, Meifeng, 30 Apr. 1963, Shanxiang Lin leg.; 2 spec., Fuzhou, Meifeng, 9 May 1963, Shanxiang Lin leg.; 9 spec., Fuzhou, Meifeng, 19 May 1963, Shanxiang Lin leg.; 10 spec., Fuzhou, Meifeng, 27 May 1963, Shanxiang Lin leg.; 6 spec., Fuzhou, Meifeng, 17 Jun. 1963, Shanxiang Lin leg.; 4 spec., Fuzhou, Meifeng, 26 Jun. 1963, Shanxiang Lin leg.; 11 spec., Fuzhou, Meifeng, 10 Jun. 1963, Shanxiang Lin leg.; 1 spec., Fuzhou, Meifeng, 31 Jun. 1963, Shanxiang Lin leg.; 3 spec., Fuzhou, Meifeng, 2 Jul. 1963, Shanxiang Lin leg.; 1 spec., Fuzhou, Meifeng, no locality, 8 Jul. 1963, Shanxiang Lin leg.; 9 spec., Fu'an, Apr. 1963, Shanxiang Lin leg.; 2 spec., Fu'an, May 1963, Shanxiang Lin leg.; 7 spec., Fuzhou, West Lake, 15 May 1963, Shanxiang Lin leg.; 1 spec., West lake, 21 May. 1963, Shanxiang Lin leg.; 2 spec., Fujian Agricultural College, 3 Jul. 1964,

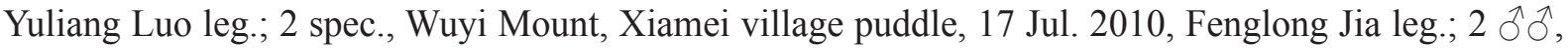
Nanjing, Hexi town, 13 Jul. 2010, Fenglong Jia leg.; 1, Xiamen, Jimei, 19 May 1964, Tongxu Peng

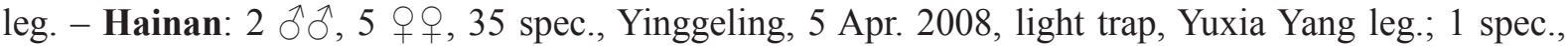
Lingshui, Diaoluoshan, 5 Jan. 1963, Zhenyao Chen leg.; 1 spec., Lingshui, Diaoluoshan, 26 Jul. 1963, Yuzhen Liang leg.; 1 spec., Lingshui, Diaoluoshan, 26 Jul. 1963, Jicai Li leg.; 2 spec., Lingshui, 
Diaoluoshan, 29 Jul. 1963, Jianqiu Tang leg.; 2 spec., Lingshui, Diaoluoshan, 31 Jul. 1963, Baiming Chen leg.; 2 spec., Lingshui, Diaoluoshan, Xiaomei, 29 Jul. 1963, Baige Chen leg.; 1 ㅇ, Bawangling, 14 Jun. 1964, Zhenyao Chen leg.; 1 spec., Wanning, Jianling, Houlang, 8-9 Apr. 2013, Weicai Xie leg.; 2 spec., Lingshui, 1 Jan. 1964, Tongxu Peng leg.; 2 spec., Jianfengling, 14 Jul. 1983, Zhihe Huang leg.; 4 spec., Jianfengling, 22 Jun. 1983, Zhihe Huang leg.; 1 spec., Jianfengling, 24 Jun. 1964, Zhenyao Chen leg.; 2 우, Xinglong, 24 Jul. 1957, Cuiying Li leg.; 1 §, Xinglong, 3 Jan. 1964, Tongxu Peng leg.; 1 spec., Sanya, 24 Jul. 1957, Zhelong Pu leg.; 1 spec., Wanning, 17 Jul. 1957, Cuiying Li leg.; 1 , Tongshi, 27 Jul. 1963, Tongxu Peng leg.; 1 spec., Haikou, 15 Jul. 1957, Zhelong Pu leg. - Jiangxi: 3

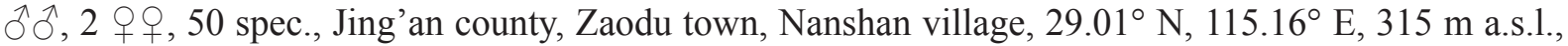
19 Jul. 2014, light trap, Renchao Lin leg.; 4 spec., Jing'an County, Guanyinyan, $29.03^{\circ} \mathrm{N}, 115.25^{\circ} \mathrm{E}$, 195 m a.s.1., 20 Jul. 2014, light trap, Renchao Lin leg.; 3 spec., Jing'an County, Daqishan Forestry Centre, $28.67^{\circ} \mathrm{N}, 115.07^{\circ} \mathrm{E}, 350 \mathrm{~m}$ a.s.l., 16 Jul. 2014, light trap, Renchao Lin leg.; 102 spec., Jing' an County, Zaodu town, Nanshan village, $29^{\circ} 01^{\prime} \mathrm{N}, 115^{\circ} 16^{\prime} \mathrm{E}, 315 \mathrm{~m}$ a.s.l., 2 Jul. 2015, light trap, Renchao Lin and Yudan Tang leg.; 10 spec., Jiulianshan, Daqiutian, 30 Aug. 2007, light trap, Hong Pang leg.; 9 spec., Jiulianshan, Daqiutian, 31 Aug. 2007, light trap, Hong Pang leg.; 12 spec., Suichuan County, Nanfengmian Nature Reserve, $26^{\circ} 17^{\prime} 04^{\prime \prime}$ N, 114 03'53" E, 816 m a.s.1., 18 Jul. 2015, Renchao Lin and Yudan Tang leg. (English labels); 9 spec., Jinggangshan, Jingzhushan, $26^{\circ} 31.01^{\prime} \mathrm{N}, 114^{\circ} 05.9^{\prime} \mathrm{E}, 640 \mathrm{~m}$ a.s.1., 4 May 2010, Fenglong Jia leg.; 2 spec., Lushan, Poyanghu, 10 Aug. 1963, Zhelong Pu leg.; 2 spec., Jiujiang, 24 Aug. 1963, Zhelong Pu leg.; 1 , Nanchang; 1 +, Jinggangshan, Luofu, 25 Apr. 2011, Weicai Xie, Zhenyu Jin and Yun Li leg. - Shaanxi: 1 ô, 1 ㅇ, 19 spec., Chang'an, Xingguoshi, 19 Aug. 1984, Zhihe Huang leg.; 2 spec., Chang'an, Quwei, 21 Jul. 1984, Zhihe Huang leg.; 2 spec., Xi'an, Chanbahe, 11 May 2011, Fenglong Jia leg.; 1 spec., Chang'an, 19 Aug. 1984, Geqiu Liang leg. Guizhou: 39 spec., Liupanshui, Panxian, 2 May. 1940; 41 spec., Dushan, 10 May 1940; 2 spec., Guiyang, 6 May 1939, Zhelong Pu leg.; 5 spec., Pingba, Maba, 13 Aug. 1982, Zhihe Huang leg.; 1 spec., Anshun, 4 May 1940, Zhelong Pu leg.; 9 spec., Weng'ang town, Maolan Nature Reserve, $25^{\circ} 15^{\prime} 08^{\prime \prime} \mathrm{N}$, 10753'56" E, 814 m a.s.1., 24 Jul. 2015, Renchao Lin and YudanTang leg. - Xizang: 2 spec., Xiachayu, no other data. - Macau: 1 ô, 2 우, Ludang City, Ecological Reserve, section one, 4-5 Apr. 2013, light trap, Fenglong Jia \& Weicai Xie leg.; 6 spec., Ludang City, Ecological Reserve, section one, 9 May 2013, light trap, Weicai Xie leg.; 8 spec., Ludang City, Ecological Reserve, section one, 9 May 2013, light trap, Jinwei Li leg.; 8 spec., Ludang City, Ecological Reserve, section one, 9 May 2013, light trap, Fenglong Jia leg.; 2 spec., Ludang City, Ecological Reserve, section one, 8 Apr. 2014, light trap, Weicai Xie leg.; 1 spec., Ludang City, Ecological Reserve, section one, 28 Apr. 2014, light trap, Fenglong Jia

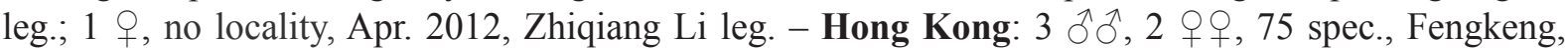
$22^{\circ} 31.695^{\prime} \mathrm{N}, 114^{\circ} 13.450^{\prime} \mathrm{E}, 13 \mathrm{~m}$ a.s.l., 9 Apr. 2014, light trap, Fenglong Jia, Weicai Xie and Jiahuang Chen leg.; 10 spec., Rongshuao, 22³2.646' N, 114¹4.926' E, 10 m a.s.1., 11 Apr. 2014, Fenglong Jia, Weicai Xie and Jiahuang Chen leg.; 2 spec., Rongshuao, 11 Jun. 2014, Weicai Xie leg.; 2 spec., Wujiaoteng, 9 Jun. 2014, Weicai Xie leg.

\section{Redescription}

FORM AND COLOUR. Body length 2.8-3.4 mm, width 1.4-1.7 mm, oblong, moderately convex. Head yellowish to blackish brown, usually frons dark and clypeus yellowish brown (Fig. 35), labrum blackish brown. Pronotum yellowish to reddish brown (Figs 32, 35-36). Elytra same colour but with pronotum sometimes with some black spots. Maxillary palps uniformly yellowish brown. Antennae yellowish brown with club somewhat dark. Labial palps reddish to yellowish brown. Ventral side yellowish brown or dark brown (Fig. 33), legs with apices of femora, tibiae and tarsomeres yellowish brown.

HEAD. Labrum with fine punctures, systematic punctures detectable. Clypeus broad, anterior margin broadly emarginate, slightly expanded in front of eyes, not impressed in front of eyes (Fig. 35), with fine and sparse punctures, systematic punctures slightly coarser than ground punctures. Eyes moderate in size, somewhat emarginate anteriorly, systematic punctures present; interval between eyes ca $4 \times$ 

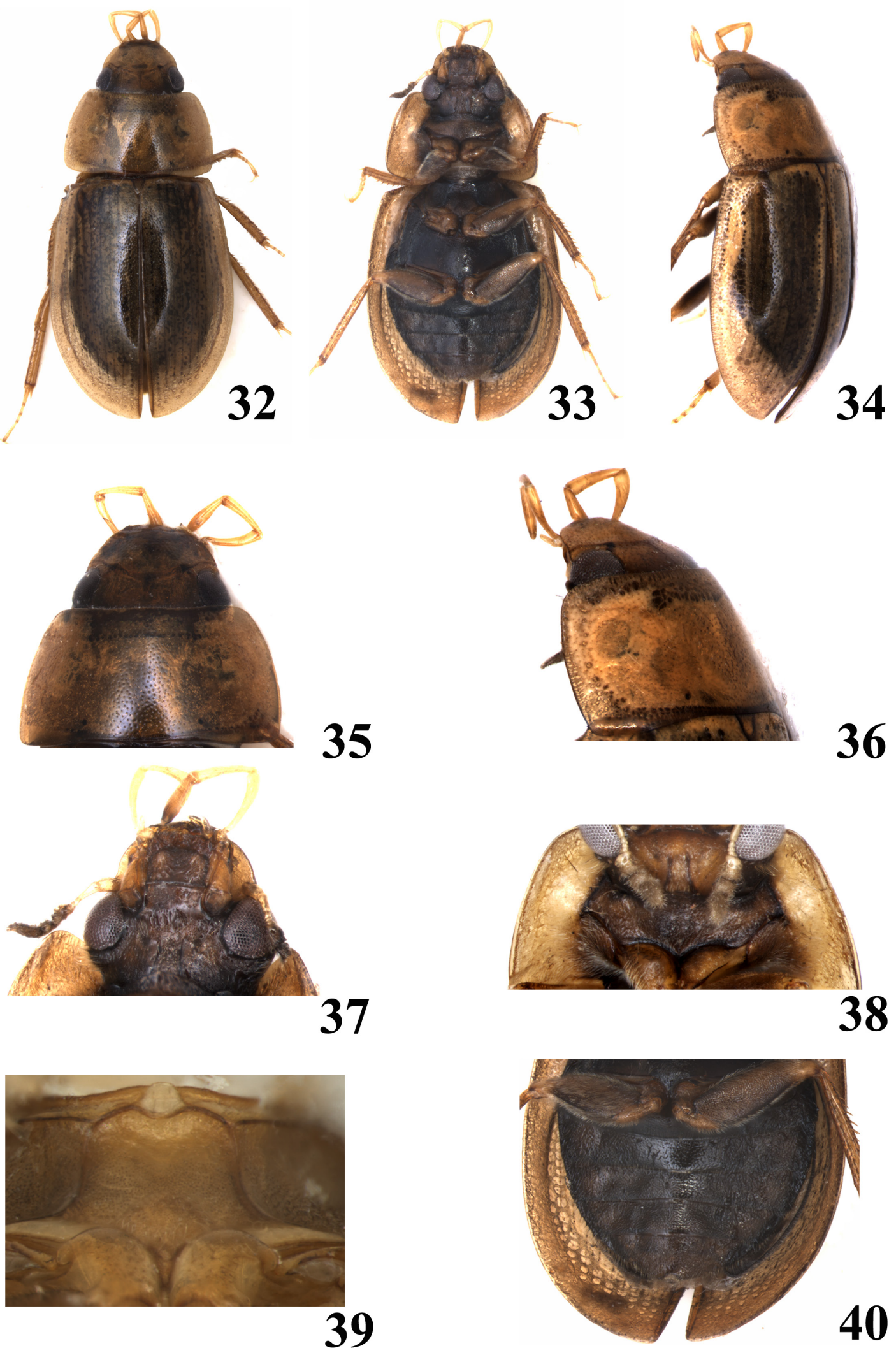

Figs 32-40. Helochares pallens (MacLeay, 1825). 32-34. Habitus. 32. Dorsal. 33. Ventral. 34. Lateral. 35. Head and pronotum. 36. Pronotum, dorsolateral. 37. Head, ventral. 38. Prosternum. 39. Mesoventrite with legs. 40. Abdomen. 
as wide as one eye. Ground punctures on frons similar to those on clypeus, systematic punctures conspicuous in front of eyes. Maxillary palps long and slender, ca $1.2 \times$ as long as width of head, $1^{\text {st }}$ and $2^{\text {nd }}$ palpomeres curved inwards, apical palpomere a little shorter than penultimate, slightly bending inwards. Antennae with 9 antennomeres, scape ca $1.5 \times$ as long as pedicel, pedicel slightly shorter than antennomeres 3-6 combined, club loosely segmented, with dense pubescence. Mentum ca $1.2 \times$ as wide as long, subquadrate, lightly impressed anteromedially, with coarse punctures, never with wrinkles (Fig. 37). Submentum with coarse punctures (Fig. 37).

THORAX. Pronotum ca $2 \times$ as wide as long, widest basally; posterior margin slightly bisinuate with median portion widely curved; ground punctures on pronotum similar to those on head, systematic punctures arranged in two transverse rows (Figs 35-36). Prosternum slightly bulging in middle, not carinate (Fig. 38), pubescent, with transverse groove, protruding anteriorly. Mesoventrite only simply convex posteromedially, without a low transverse ridge (Fig. 39). Metaventrite pubescent, with somewhat convex middle portion, without glabrous area. Metepisterna ca $3.5 \times$ as long as wide, subparallel. Scutellum triangular, with similar punctures as on elytra. Ground punctures on elytra similar to those on pronotum, with three conspicuous rows of systematic punctures, dorsal surface without striae but 8-9 striae on underside of elytra usually visible from dorsal side (Figs 41-42) (continuous dark lines with black spots on ventral surface of the elytra, not corresponding with real punctures on dorsal elytral surface, and sometimes not clear in old specimens). Epipleura very wide anteriorly, gradually narrowed, reaching level of first visible abdominal sternite. Femora densely pubescent with apical eighth glabrous (Figs 33, 40). Metatarsomeres with dense white hairs ventrally and some long swimming hairs dorsally. Claws of moderate size, rather strongly curved.

AвDomen. All visible abdominal ventrites with dense pubescence; first ventrite not carinate (Fig. 40).

AEDEAGus. Apex of parameres not dilated inwards, somewhat narrowly rounded near apex. Membranous inner sac with several small dentiform bulges on each side. Median lobe with sharp apex, apex spineformed (Fig. 52).

\section{Differential diagnosis}

This species may be closest to H. obscurus (Müller, 1776) based on form and colour. It can be distinguished from $H$. obscurus by its smaller size, dorsum with fine punctures, striae on the underside of the elytra usually visible in dorsal view, mesoventrite only simply convex posteromedially, without a transverse ridge or process pointed posteriorly, apex of parameres not dilated inwards and median lobe with a spine-formed apex.

\section{Habitat}

Wingspread and occupying typical aquatic habitats such as ponds with rotting leaves, margins of puddles and edges of rivers. It usually flies when it is collected from water and its body surface becomes drier during the daytime. Adults have strong photokinesis and sometimes hundreds of individuals appear at light.

\section{Distribution}

China (Chongqing, Fujian, Guangdong, Guangxi, Guizhou, Hainan, Hubei, Hunan, Jiangxi, Macau, Shaanxi, Sichuan, Yunnan, Xizang). Afrotropical: Benin, Botswana, Chad, Congo, Ethiopia, Ghana, Guinea, Kenya, Madagascar, Namibia, Rwanda, South Africa, Sudan, Tanzania, Zambia (BalfourBrowne 1951, 1952, 1957; Hebauer 1996). Palearctic: China, Egypt, Israel, Japan, Lebanon, Saudi Arabia (north), Turkey, Yemen. Oriental: Bangladesh, Burma, China, India, Indonesia (Java, Sumatra, Sunda), Malaysia (peninsula), Nepal, Philippines, Sri Lanka, Thailand (Fikáček et al. 2015; Hansen 1999; Jäch et al. 2012 ). New record for Chongqing and Macau. 

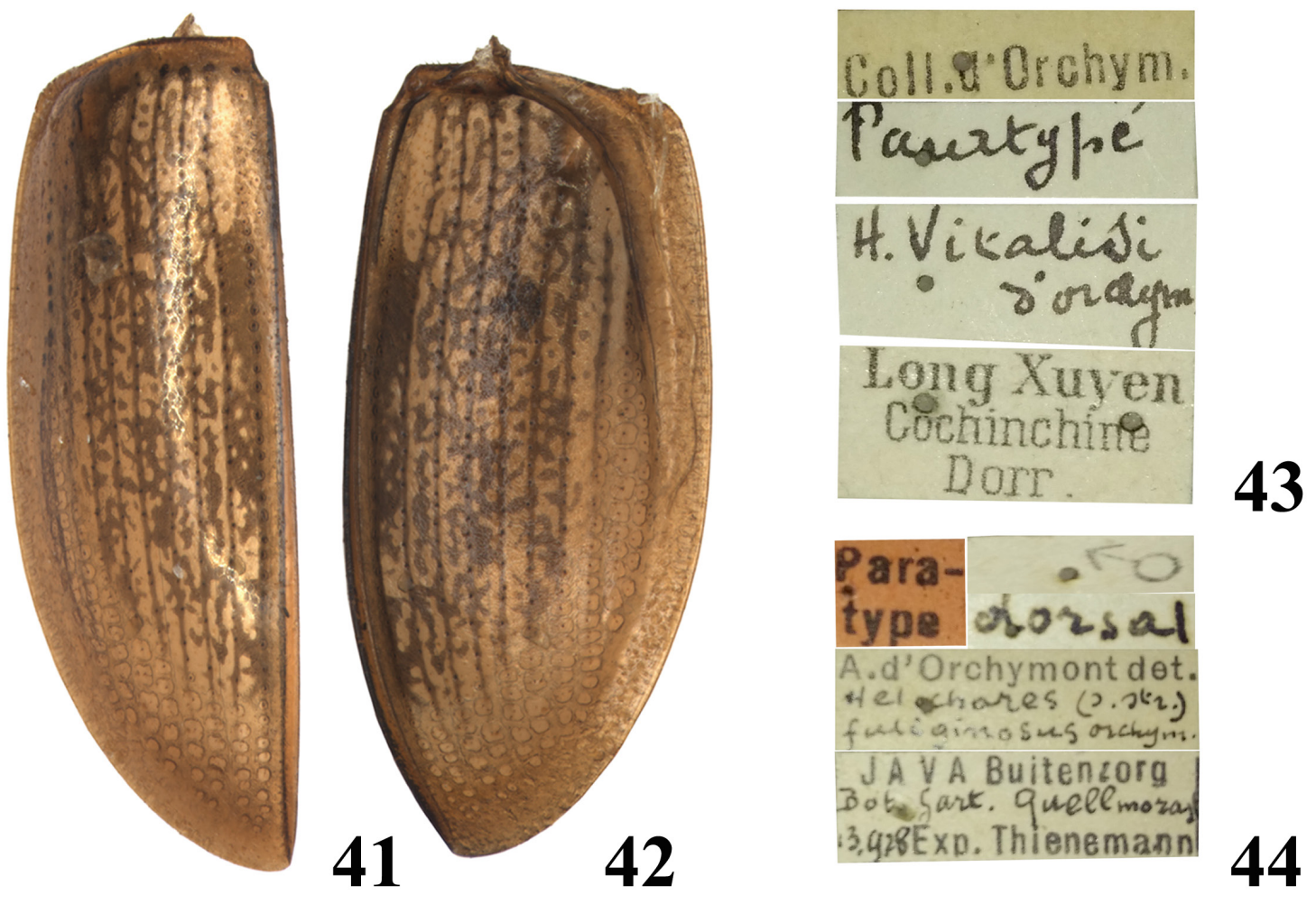

44
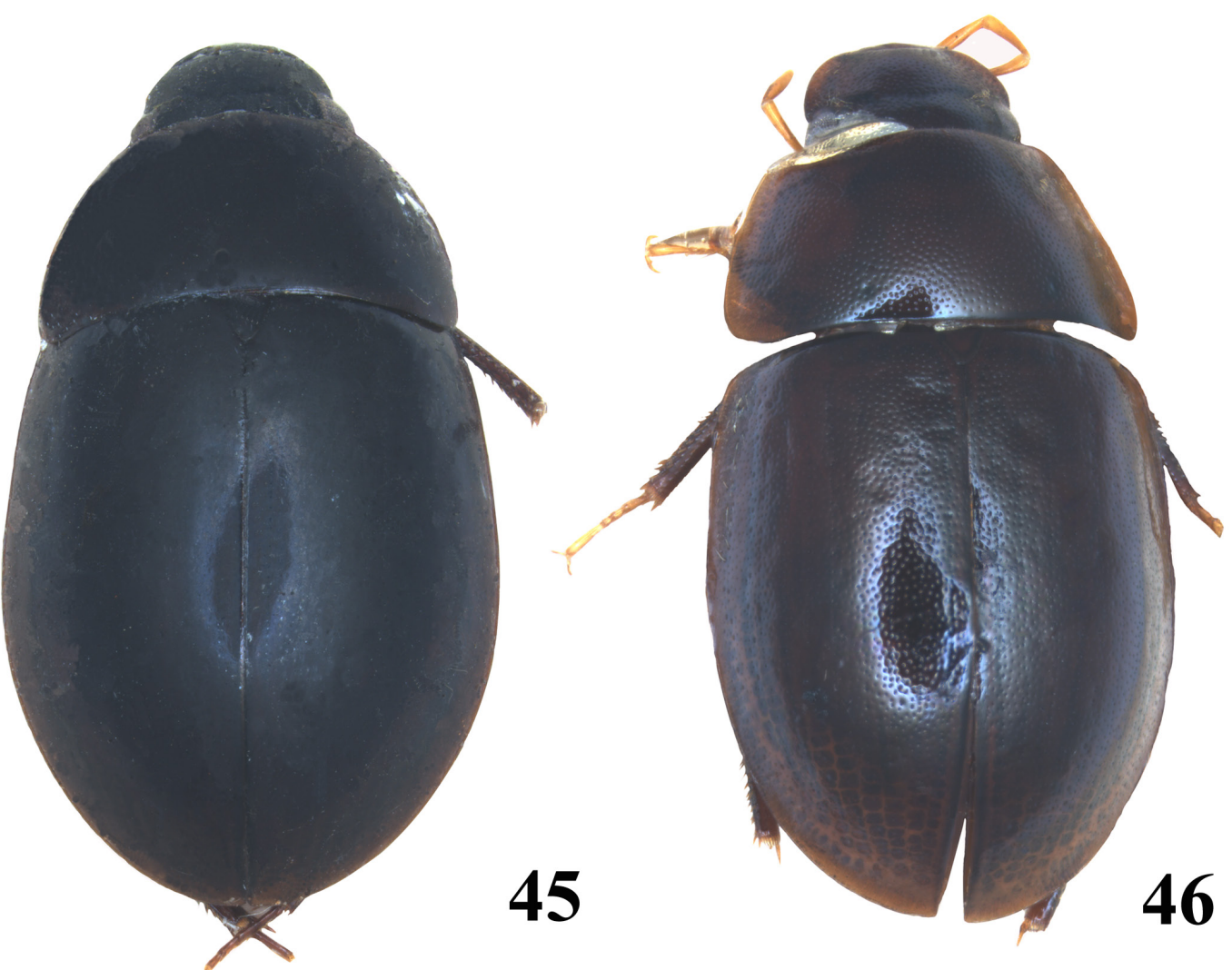

Figs 41-46. - 41-42. Helochares pallens (MacLeay, 1825). Elytra. 41. Dorsal. 42. Ventral. 43, 45. Paratype of $H$. vitalisi d'Orchymont, 1919. 43. Data of labels. 45. Habitus, dorsal. 44, 46. Paratype of $H$. fuliginosus d'Orchymont, 1932. 44. Data of labels. 46. Habitus, dorsal. 


\section{A key to the species of Helochares (s. str.) of China}

1. Elytra with 10 striae and scutellary stria, punctures in striae coarser than systematic punctures ..... ...Subgenus Hydrobaticus MacLeay, 1871

- Elytra without striae or series of punctures except for the rows of systematic punctures, without scutellary stria ......(Subgenus Helochares (s. str.) Mulsant, 1844) ..............................................2

2. Size small, 2.8-3.4 $\mathrm{mm}$ in length. Dorsum yellowish or reddish brown with dark labrum and frons (Figs 32, 34), pronotum and elytra never dark brown or black. Mesoventrite only simply convex posteromedially, without a transverse ridge or process pointed posteriorly (Fig. 39)

H. pallens (MacLeay, 1825)

- Size over $3.6 \mathrm{~mm}$ in length. Dorsum dark brown or black, if yellowish or reddish brown, then size over $4.9 \mathrm{~mm}$. Mesoventrite with a transverse ridge or a process (Figs 7, 15, 24, 30)

3. Dark brown or black with very fine ground punctures, clypeus with systematic punctures distinctly larger than ground punctation. Mesoventrite with a stout, backward pointing projection (Fig. 24). Parameres with 3 branches on apical third (Figs 50-51)

H. atropiceus Régimbart, 1903

- Dorsum yellowish brown, dark brown or black with coarser ground punctures, systematic punctures on clypeus almost of the same size as ground punctures. Mesoventrite with a transverse ridge (Figs 7, 15, 30), without backward projection. Parameres without branches (Figs 47-48, 52-55)

4. Yellowish or reddish brown with dark brown labrum, never dark brown or black (Fig. 26). Clypeus at most slightly expanded, not impressed in front of eyes. Elytra usually with some longitudinal rows of black spots (Fig. 26). Dorsum with coarser punctures, systematic punctures usually somewhat indistinct (Figs 26, 28). Median lobe of aedeagus with spiniform apex (Figs 53-55) ……………………………………........................... obscurus (Müller, 1776)

- Dark brown or black, pronotum with yellowish brown lateral margin (Figs 1, 9). Clypeus more expanded, distinctly impressed in front of eyes (Figs 4, 14). Elytra without longitudinal rows of black spots. Median lobe of aedeagus with broad apex (Figs 47-49)

5. Body length 4.8-5.3 mm. Lateral margin of clypeus and elytra with same colour as disc (Figs 1, 3-4); pronotum and elytra more coarsely punctate; maxillary palps dark brown or black, each palpomere clearly lighter (Fig. 4). Aedeagus slender, parameres ca $10 \times$ as long as width of apex, apex with a small dent inwards (Figs 48-49)

H. songi sp. nov.

- Body length 3.6-4.3 mm. Clypeus and elytra with light colour laterally (Figs 11, 14); pronotum and elytra with finer and sparser punctures; maxillary palps uniformly yellowish brown (Figs 12-14). Length of parameres ca $6.5 \times$ width of apex, subparallel, apex without small dent inwards (Fig. 47); median lobe expanded subapically, abruptly narrowed apically (Fig. 47) ..

H. fuliginosus d'Orchymont, 1932

\section{Discussion}

As to the Chinese fauna of Helochares (s. str.), the diversity of Oriental components is higher than that of Palearctic components. The representatives of this subgenus in the Palearctic are only known from Shaanxi and Xinjiang, in which H. obscurus (Müller, 1776) is only known from Xinjiang, where it is not common. This is probably the southernmost border of its distribution. H. pallens (MacLeay, 1825), a very abundant species in South and Southwest China, was collected from Shaanxi at the northern foot of the Qinling Mountains. No other material of $H$. pallens has been gathered at more northerly localities, although several expeditions have sampled the area. The northernmost border of this species is probably the Qinling Mountains. Surprisingly, no representatives of this subgenus have hitherto been found in 

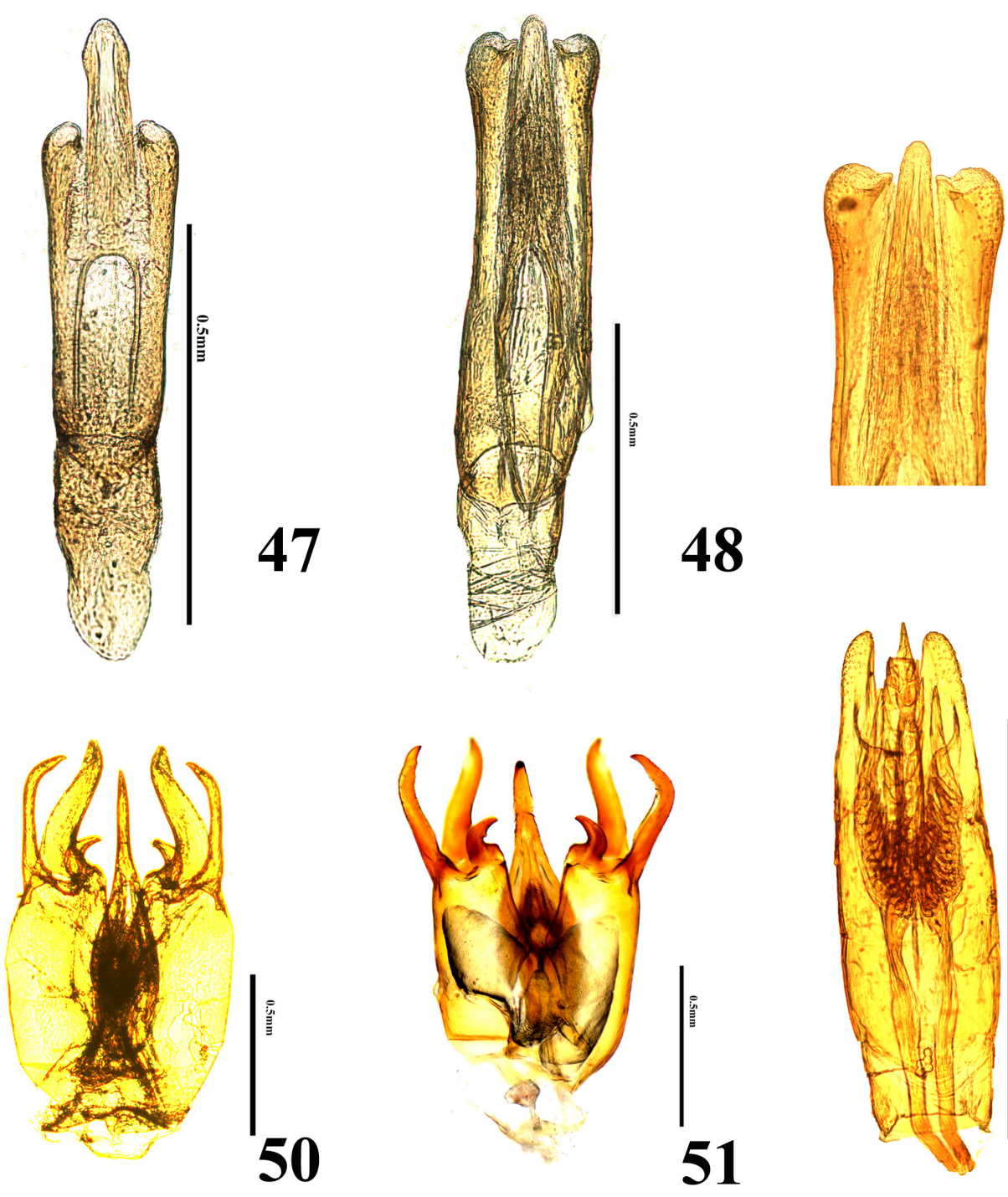

48

49
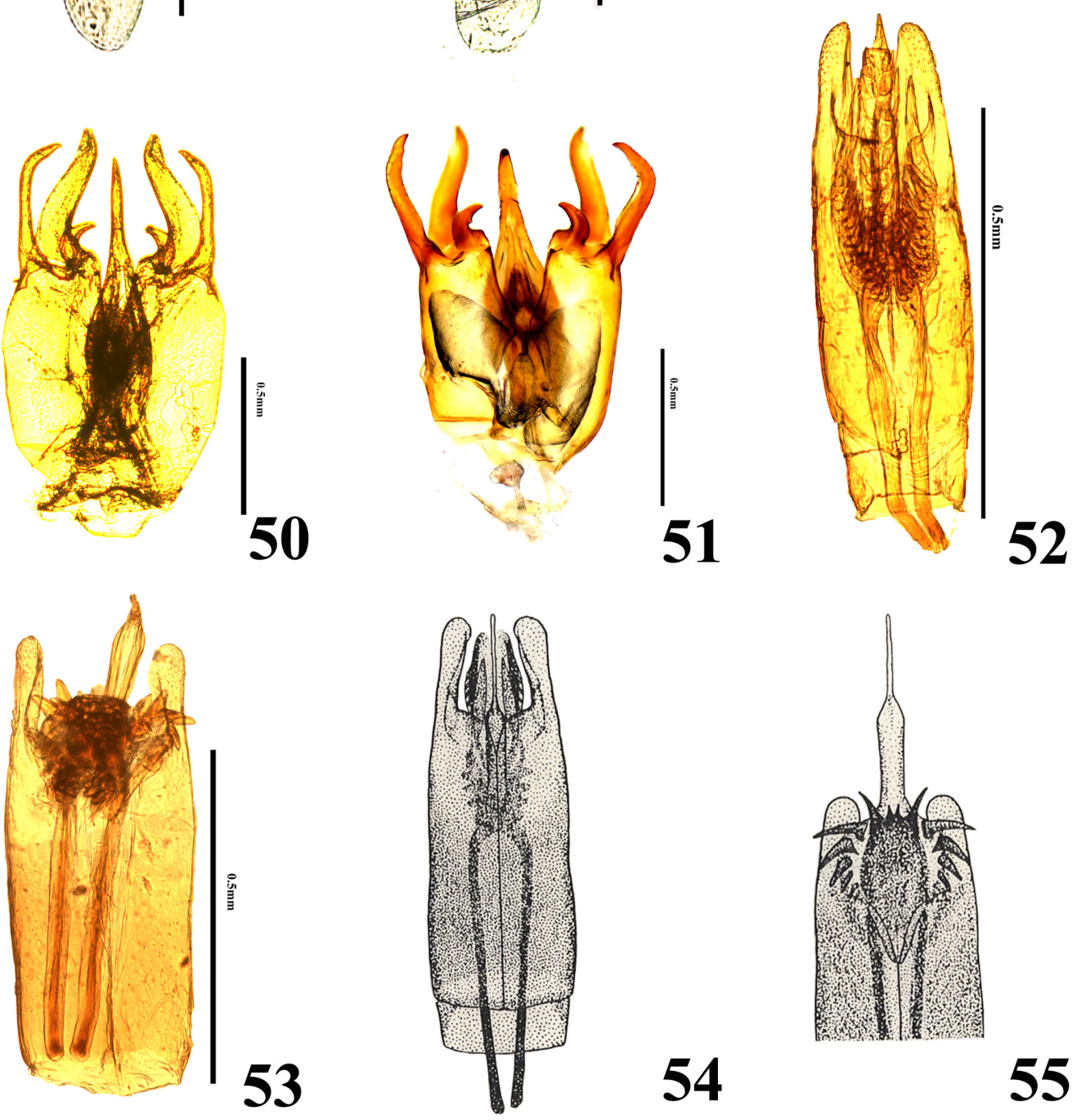

Figs 47-55. Aedeagi in species of Helochares Mulsant, 1844. 47. H. fuliginosus d'Orchymont, 1932. 48-49. H. songi sp. nov. 50-51. H. atropiceus Régimbart, 1903. 50. From Guangxi. 51. From Hong Kong. 52. H. pallens (MacLeay, 1825). 53-55. H. obscurus (Müller, 1776). 53. From Xinjiang. 54-55. After Hansen (1987). 
North and Northeast China, as well as north of the Yangtze River in Central and East China, even though many expeditions have been conducted there by the senior author. Helochares pallens may be expected to be found from north of the Yangtze River in the future.

The purpose of this manuscript is to contribute to our understanding of the fauna of Helochares (s. str.) in China. However, a phylogenetic analysis or a re-assessment of the subgenus are far beyond the scope of this work.

\section{Acknowledgements}

We are indebted to Dr. Yûsuke N. Minoshima (Natural History Division, Kitakyushu Museum of Natural History and Human History, Japan), to Dr. Robert B. Angus (BMNH) and to an anonymous reviewer for their reviews of the manuscript. We are grateful to Dr. Martin Fikáček (NMPC), who loaned a specimen of Helochares fuliginosus d'Orchymont to the authors, and reviewed the manuscript. We are also grateful to Dr. Jiří Hájek (NMPC) for his kind help to the senior author when he studied specimens of Helochares at NMPC. Special thanks are given to Dr. Pol Limbourg (IRSN), who provided an opportunity to the senior author to study the type of H. fuliginous d'Orchymont in the d'Orchymont Collection. This study was supported by the National Natural Science Foundation of China (grants 31772494, 31272266).

\section{References}

Balfour-Browne J. 1950. Palpcornia. Exploration du Parc National Albert, Mission G.F. de Witte (193335) 63: 1-84.

Balfour-Browne J. 1951. Coleoptera: Haliplidae, Dytiscidae, Gyrinidae, Hydraenidae, Hydrophilidae. In: British Museum (Natural History) (eds) Expedition to South-west Arabia 1937-1938: 179-220.

Balfour-Browne J. 1952. Mission A. Villiers au Togo et au Dahomey (1950). VII. Coléoptères hydrophilides. Bulletin de l'Institut français d'Afrique noire 14: 126-139.

Balfour-Browne J. 1957. Contributions à l'étude de la faune entomologique du Ruanda-Urundi (Mission P. Basilewsky 1953). CXVIII. Coleoptera Hydrophilidae. Annales du Musée royal du Congo Belge, Zoologie 58: 14-25.

Bedel L. 1881. Faune des coléoptères du bassin de la Seine. Vol. 1. Annales de la Société entomologique de France 24 (Appendix): 257-360.

Blackburn T. 1898. Further notes on Australian Coleoptera, with descriptions of new genera and species. XXIV. Palpicornes. Transactions of the Royal Society of South Australia 22: 221-233. Available from https://biodiversitylibrary.org/page/16137901 [accessed 11 Apr. 2018].

Dahl G. 1823. Coleoptera und Lepidoptera. Ein systematisches Verzeichniss mit beygesetzten Preisen der Vorräthe. J.E. Akkermann, Vienna. https://doi.org/10.5962/bhl.title.124180

Fabricius J.C. 1792. Entomologia Systematica emendata et aucta, secundum Classes, Ordines, Genera, Species, adjectis Synonymis, Locis, Observationibus, Descriptionibus. Vol. 1, part 1. C.G. Proft, Hafniae [Copenhagen]. Available from https://biodiversitylibrary.org/page/51985494 [accessed 11 Apr. 2018].

Fikáček M., Angus R.B., Gentili E., Jia F., Minoshima Y. N., Prokin A., Przevozny M. \& Ryndevich S.K. 2015. Helophoridae, Hydrochidae, Hydrophilidae. In: Löbl I. \& Löbl D. (eds) Catalogue of Palaearctic Coleoptera. Vol. 2/1 (revised and updated edition), Hydrophiloidea - Staphylinoidea. Brill, Leiden, Boston.

Gemminger M. \& Harold B. 1868. Catalogus Coleopterorum hucusque Descriptorum Synonymicus et Systematicus. Vol. 2: 425-752. E.H. Gummi, Monachii [Munich].

Available from https://biodiversitylibrary.org/page/10174177 [accessed 11 Apr. 2018]. 
Gyllenhal L. 1808. Insecta Suecica. Vol. 1, part 1. F.J. Leverentz, Scaris [Skara, Sweden]. Available from https://biodiversitylibrary.org/page/9330983 [accessed 11 Apr. 2018].

Hansen M. 1987. The Hydrophiloidea (Coleoptera) of Fennoscandia and Denmark. Fauna Entomologica Scandinavica 18: 1-254.

Hansen M. 1991. The hydrophiloid beetles. Phylogeny, classification and a revision of the genera (Coleoptera, Hydrophiloidea). Biologiske Skrifter 40: 1-368.

Hansen M. 1999. World Catalogue of Insects 2: Hydrophiloidea (s. str.) (Coleoptera). Apollo Books, Stenstrup, Denmark.

Hebauer F. 1995. Neues zu den Acidocerina Hansen (Helocharae d'Orchymont) der indomalaiischen Region (Coleoptera, Hydrophilidae). Acta Coleopterologica 11 (3): 3-14.

Hebauer F. 1996. Synopsis der afrikanischen Arten der Gattung Helochares Mulsant (Coleoptera, Hydrophilidae). Acta Coleopterologica 12 (2): 3-38.

Hebauer F. 1999. Neue und wenig bekannte Hydrophiloidea aus dem südlichen Afrika (Coleoptera: Hydrophiloidea). Acta Coleopterologica 15 (2): 7-16.

Hebauer F. 2001. The real Helochares taprobanicus Sharp, 1890 and its allies (Coleoptera: Hydrophilidae). Lattisimus 14: 10-16.

Hebauer F. 2002. New Hydrophilidae of the Old World (Coleoptera: Hydrophilidae). Acta Coleopterologica 18 (3): 3-24.

Hebauer F. 2003. A new species of the genus Helochares (Coleoptera, Hydrophilidae) from Africa. Special Bulletin of the Japanese Society of Coleopterology 6: 129-132.

Hebauer F., Hendrich L. \& Balke M. 1999. A contribution to the knowledge of the water beetle fauna (Col. Hydradephaga, Hydrophiloidea and Staphylinoidea) of a tropical freshwater lake: Tasek Cini, Pahang, West Malaysia. Raffles Bulletin of Zoology 47 (2): 333-348.

Herbst J.F.W. 1797. Natursystem aller bekannten in- und ausländischen Insekten. Der Käfer 7. Pauli, Berlin.

Jäch M.A., Li J., Zhang X. \& Gao M. 2012. A remarkable collection of aquatic and riparian beetles from Xiachayu, Zayü County, southeastern Tibet (Coleoptera: Gyrinidae, Noteridae, Dytiscidae, Spercheidae, Hydrophilidae, Heteroceridaea, Limnichidae). Koleopterologische Rundschau 82: 65-69.

Jia F., Wang J., Wang J.-F. \& Deng R. 2010. Two species of hydrophilid beetles (Coleoptera: Hydrophilidae) new to China. Entomotaxonomia 32 (1): 33-35. [In Chinese.]

Komarek A. 2004. Taxonomic revision of Anacaena Thomson, 1859. I. Afrotropical species (Coleoptera: Hydrophilidae). Koleopterologische Rundschau 74: 303-349.

Kuwert A. 1890. Bestimmungs-Tabellen der Hydrophiliden Europas, Westasiens und Nordafrikas. Verhandlungen des naturforschenden Vereins in Brünn 28: 1-121.

Available from https://biodiversitylibrary.org/page/43763386 [accessed 11 Apr. 2018].

MacLeay W.S. 1825. Annulosa Javanica or an Attempt to Illustrate the Natural Affinities and Analogies of the Insects Collected in Java by Thomas Horsfield, M.D. F.L. \& G.S. and Deposited by him in the Museum of the Honourable East-India Company. Kingsbury, Parbury and Allen, London. Available from https://biodiversitylibrary.org/page/12819790 [accessed 6 Apr. 2018].

Mart A., İncekara U. \& Karaca H. 2010. A new species and new records of Hydrophilidae (Coleoptera) from Turkey. Turkish Journal of Zoology 34: 297-303. https://doi.org/10.3906/zoo-0905-29 
Montrouzier P. 1860. Essai sur la faune entomologique de la Nouvelle-Calédonie (Balade) et des îles de Pins, Art, Lifu, etc. Annales de la Société entomologique de France, Série 3 8: 229-308.

Available from https://biodiversitylibrary.org/page/30253077 [accessed 11 Apr. 2018].

Motschulsky V. 1845. Remarques sur la collection de coléoptères russes. 1. Bulletin de la Société impériale des Naturalistes de Moscou 18 (1-2): 3-127.

Available from https://biodiversitylibrary.org/page/44164948 [accessed 11 Apr. 2018].

Motschulsky V. 1853. Hydrocanthares de la Russie. Société de Littérature Finnoise, Helsingfors [Helsinki].

Müller O.F. 1776. Zoologicae Danica Prodromus, seu Animalium Danice et Norvegice indigenarum Characteres, Nomina et Synonyma imprimis Popularium. Hallager, Havniæ [Copenhagen].

https://doi.org/10.5962/bhl.title.13268

Mulsant E. 1844. Histoire Naturelle des Coléoptères de France. Vol. 5. Palpicornes. L. Maison, Paris; Ch. Savy Jeune, Lyon.

Available from https://biodiversitylibrary.org/page/9628710 [accessed 11 Apr. 2018].

d'Orchymont A. 1919a. Matériaux pour servir a l'étude de la faune entomologique de l'Indo-Chine. Palpicornia (Col.). Annales de la Société entomologique de Belgique 59: 70-83.

Available from https://biodiversitylibrary.org/page/12281533 [accessed 6 Apr. 2018].

d'Orchymont A. 1919b. Contribution a l'étude des sous-familles des Sphaeridiinae et des Hydrophilinae (Col. Hydrophilidae). Annales de la Société entomologique de France 88: 105-168. Available from https://biodiversitylibrary.org/page/9486175 [accessed 6 Apr. 2018].

d'Orchymont A. 1919c. Les genres Enochroides Kuw., Neohydrobius Blackb. et Hygrotrophus W. McLeay (Col. Palpicornia). Bulletin de la Société entomologique de France for 1919: 226-230. Available from https://biodiversitylibrary.org/page/9488388 [accessed 6 Apr. 2018].

d'Orchymont A. 1926. Contribution à l'étude des hydrophilides VI. Bulletin et Annales de la Société entomologique de Belgique 66: 201-248.

d'Orchymont A. 1932. Zur Kenntnis der Kolbenwasserkäfer (Palpicornia) von Sumatra, Java und Bali. Archiv für Hydrobiologie, Supplement IX (Tropische Binnengewässer II): 623-714.

d'Orchymont A. 1933. Contribution à l'étude des Palpicornia VIII. Bulletin et Annales de la Société entomologique de Belgique 73: 271-314.

d'Orchymont A. 1935. Aquatic insects of China. XX. Catalogue of Chinese Palpicornia (Order Coleoptera). Peking Natural History Bulletin 9: 185-225.

Régimbart M. 1903. Contribution à la faune Indo-Chinoise. 19e mémoire. Hydrophilidae. Annales de la Société entomologique de France 72: 52-64.

Available from https://biodiversitylibrary.org/page/8247940 [accessed 6 Apr. 2018].

Régimbart M. 1906. Voyage de M. Ch. Alluaud dans l'Afrique Orientale. Dytiscidae, Gyrinidae, Hydrophilidae. Annales de la Société entomologique de France 75: 235-278.

Available from https://biodiversitylibrary.org/page/9207127 [accessed 11 Apr. 2018].

Reiche L. 1854. Catalogue des espèces d'Insectes Coléoptères recueillies par M. F. de Saulcy pendant son Voyage en Orient. Gide \& J. Baudry, Paris.

Reiche L. \& Saulcy F. 1856. Espèces nouvelles ou peu connues de coléoptères, recueillies par M. F. de Saulcy, membre de l'Institut, dans son voyage en Orient. Annales de la Société entomologique de France, Série 3 4: 353-422.

Available from https://biodiversitylibrary.org/page/8248901 [accessed 11 Apr. 2018]. 
Reitter E. 1909. Fauna Germanica. Die Käfer des Deutschen Reiches. Vol. 2. K.G. Lutz, Stuttgart.

Rey C. 1885. Descriptions de coléoptères nouveaux ou peu connus de la tribu des Palpicornes. Annales de la Société linnéenne de Lyon 31: 13-32. Available from https://biodiversitylibrary.org/page/54600262 [accessed 11 Apr. 2018].

Sahlberg J. 1913. Coleoptera balcanica quae mensibus Octobri et Decembri 1903 atque Martis et Aprili 1906 in peninsula balcanica collegerunt John Sahlberg et Unio Saalas. Öfversigt av Finska VetenskapsSocietetens Förhandlingar 55A (15): 1-108.

Available from https://biodiversitylibrary.org/page/14567987 [accessed 11 Apr. 2018].

Satô M. 1976. Two Helochares-species from the Ryukyus (Hydrophilidae). Entomological Review of Japan 29: 21-24.

Sharp D. 1873. The water beetles of Japan. Transactions of the Entomological Society of London 1873: 45-67. Available from https://biodiversitylibrary.org/page/14774477 [accessed 11 Apr. 2018].

Sharp D. 1903. Water-beetles (Dytiscidae \& Hydrophilidae) of the Swedish Zoological Expedition to Egypt and the White Nile. In: Jägerskiöld L.A. (ed.) Results of the Swedish Zoological Expedition to Egypt and the White Nile 1901 under the Direction of L.A. Jägerskiöld. Part I (10). Library of the Royal University of Uppsala, Uppsala, Sweden. Available from https://biodiversitylibrary.org/page/18760768 [accessed 11 Apr. 2018].

Short A.E.Z. 2005. A review of the subtribe Acidocerina with special reference to Costa Rica (Coleoptera: Hydrophilidae). Koleopterologische Rundschau 75: 191-226.

Short A.E.Z. \& Fikáček M. 2011. World catalogue of the Hydrophiloidea (Coleoptera): additions and corrections II (2006-2010). Acta Entomologica Musei Nationalis Pragae 51 (1): 83-122.

Short A.E.Z. \& Hebauer F. 2006. World Catalogue of Hydrophiloidea - additions and corrections I (1999-2005) (Coleoptera). Koleopterologische Rundschau 76: 315-395.

Zaitzev F.A. 1908. Catalogue des coléoptères aquatiques des familles Dryopidae, Georyssidae, Cyathoceridae, Heteroceridae et Hydrophilidae. Horae Societatis entomologicae rossicae 38: 283-420.

Manuscript received: 24 May 2017

Manuscript accepted: 9 February 2018

Published on: 24 May 2018

Topic editor: Gavin Broad

Desk editor: Danny Eibye-Jacobsen

Printed versions of all papers are also deposited in the libraries of the institutes that are members of the EJT consortium: Muséum national d'Histoire naturelle, Paris, France; Botanic Garden Meise, Belgium; Royal Museum for Central Africa, Tervuren, Belgium; Natural History Museum, London, United Kingdom; Royal Belgian Institute of Natural Sciences, Brussels, Belgium; Natural History Museum of Denmark, Copenhagen, Denmark; Naturalis Biodiversity Center, Leiden, the Netherlands; Museo Nacional de Ciencias Naturales-CSIC, Madrid, Spain; Real Jardín Botánico de Madrid CSIC, Spain; Zoological Research Museum Alexander Koenig, Bonn, Germany. 